NBER WORKING PAPER SERIES

FISCAL FORESIGHT AND INFORMATION FLOWS

\author{
Eric M. Leeper \\ Todd B. Walker \\ Shu-Chun Susan Yang \\ Working Paper 14630 \\ http://www.nber.org/papers/w14630 \\ NATIONAL BUREAU OF ECONOMIC RESEARCH \\ 1050 Massachusetts Avenue \\ Cambridge, MA 02138 \\ January 2009
}

Leeper acknowledges support of NSF Grant SES-0452599. Most of this research was done while Yang was at Academia Sinica. We also acknowledge comments by Troy Davig, Dale Henderson, Beth Klee, Karel Mertens, Ricardo Nunes, Morten Ravn, Chris Sims, and participants at presentations at the Congressional Budget Office, the Federal Reserve Board, the Reserve Bank of New Zealand, Sveriges Riksbank, the Bank of Korea Conference "Recognizing and Coping with Macroeconomic Model Uncertainty in Designing Monetary Policy," the Third International Conference on Macroeconomics in Madrid, UCSD, UC-Irvine, Federal Reserve Bank of Atlanta, University of Auckland, University of Otago, University of Canterbury, and Victoria University of Wellington. We are particularly grateful to Jim Nason and Harald Uhlig for helpful comments. The views expressed in this paper are those of authors and should not be interpreted as those of the Congressional Budget Office nor of the National Bureau of Economic Research.

NBER working papers are circulated for discussion and comment purposes. They have not been peerreviewed or been subject to the review by the NBER Board of Directors that accompanies official NBER publications.

(C) 2009 by Eric M. Leeper, Todd B. Walker, and Shu-Chun Susan Yang. All rights reserved. Short sections of text, not to exceed two paragraphs, may be quoted without explicit permission provided that full credit, including $(\mathcal{O}$ notice, is given to the source. 
Fiscal Foresight and Information Flows

Eric M. Leeper, Todd B. Walker, and Shu-Chun Susan Yang

NBER Working Paper No. 14630

January 2009

JEL No. E3,E6

\begin{abstract}
$\underline{\text { ABSTRACT }}$
Fiscal foresight -- the phenomenon that legislative and implementation lags ensure that private agents receive clear signals about the tax rates they face in the future -- is intrinsic to the tax policy process. This paper develops an analytical framework to study the econometric implications of fiscal foresight. Simple theoretical examples show that foresight produces equilibrium time series with nonfundamental representations, which misalign the agents' and the econometrician's information sets. Economically meaningful shocks to taxes, therefore, cannot generally be extracted from statistical innovations in conventional ways. Econometric analyses that fail to align agents' and the econometrician's information sets can produce distorted inferences about the effects of tax policies. The paper documents the sensitivity of econometric inferences of tax effects to details about how tax information flows into the economy. We show that alternative assumptions about the information flows that give rise to fiscal foresight can reconcile the diverse empirical findings in the literature on anticipated tax changes.
\end{abstract}

Eric M. Leeper

Department of Economics

304 Wylie Hall

Indiana University

Bloomington, IN 47405

and NBER

eleeper@indiana.edu

Todd B. Walker

Department of Economics

105 Wylie Hall

Indiana University

Bloomington, IN 47405

walkertb@indiana.edu
Shu-Chun Susan Yang

Congressional Budget Office

Washington, DC 20515

susan.yang@cbo.gov 


\title{
FISCAL FORESIGHT AND INFORMATION FLOWS
}

\author{
ERIC M. LEEPER, TODD B. WALKER, AND SHU-CHUN SUSAN YANG
}

\section{INTRODUCTION}

Fiscal policy presents researchers with a unique empirical challenge: how to identify and quantify the impacts of foreseen "shocks" to taxes. The challenge posed by taxes is unique because few economic phenomena provide economic agents with such clear signals about how important margins will change in the future. Intrinsic to the process of changing taxes are two kinds of lags: the legislative lag, between when new tax law is proposed and when it is passed, and the implementation lag, between when the legislation is signed into law and when it actually takes effect. Estimates of the total lag range from a couple of months to two years or more, depending on the particular legislation being considered [Steigerwald and Stuart (1997), Romer and Romer (2007b), Yang (2008)].

Public finance economists recognize the possibility of fiscal foresight and have accumulated empirical evidence of its importance using a variety of econometric and event-study techniques. ${ }^{1}$ Macroeconomists have acknowledged the possibility of fiscal foresight in empirical work, but the empirics are typically not solidly grounded in theory. This paper is the first theoretical attempt to systematically study the econometric implications of fiscal foresight.

Empirical findings from macroeconomic time series about the impacts of fiscal foresight are all over the map. ${ }^{2}$ Existing work concludes that an anticipated cut in taxes may have little or no effect [Poterba (1988), Blanchard and Perotti (2002), Romer and Romer (2007a)], may be expansionary in the short run [Mountford and Uhlig (2008)], or may be contractionary in the short run [Branson, Fraga, and Johnson (1986), House and Shapiro (2006), Mertens and Ravn (2008)]. We use simple analytical examples and a dynamic stochastic general

Date: January 21, 2009. Department of Economics, Indiana University and NBER, eleeper@indiana.edu; Department of Economics, Indiana University, walkertb@indiana.edu; Congressional Budget Office, susan.yang@cbo.gov. Leeper acknowledges support of NSF Grant SES-0452599. Most of this research was done while Yang was at Academia Sinica. We also acknowledge comments by Troy Davig, Dale Henderson, Beth Klee, Karel Mertens, Ricardo Nunes, Morten Ravn, Chris Sims, and participants at presentations at the Congressional Budget Office, the Federal Reserve Board, the Reserve Bank of New Zealand, Sveriges Riksbank, the Bank of Korea Conference "Recognizing and Coping with Macroeconomic Model Uncertainty in Designing Monetary Policy," the Third International Conference on Macroeconomics in Madrid, UCSD, UC-Irvine, Federal Reserve Bank of Atlanta, University of Auckland, University of Otago, University of Canterbury, and Victoria University of Wellington. We are particularly grateful to Jim Nason and Harald Uhlig for helpful comments. The views expressed in this paper are those of authors and should not be interpreted as those of the Congressional Budget Office.

${ }^{1}$ Evidence of foresight leading up to the Tax Reform Act of 1986 is documented in Auerbach and Slemrod (1997) and Burman, Clausing, and O'Hare (1994).

${ }^{2}$ The problems associated with fiscal foresight apply with equal force to estimated dynamic stochastic general equilibrium models of fiscal policy, such as Braun (1994), McGrattan (1994), Coenen and Straub (2004), Forni, Monteforte, and Sessa (2006), or Kamps (2007). 
equilibrium (DSGE) model calibrated to U.S. data to rationalize these diverse findings as the outcomes of alternative assumptions about the information sets underlying empirical work.

Theory suggests that fiscal foresight poses a substantial challenge to econometric analyses of fiscal policy. Foresight creates an equilibrium in which the information sets of economic agents and the econometrician tend to be misaligned, with agents basing their choices on more information than the econometrician possesses. Structural shocks to tax policy, then, cannot be recovered from current and past fiscal data, a central assumption of conventional econometric methods. Instead, conventional methods can lead the econometrician to label as "tax shocks" objects that are linear combinations of all the exogenous disturbances at various leads and lags.

An important finding of the paper is that econometric inferences about tax effects can be highly sensitive to details about how information about taxes flows to economic decision makers. Information flows determine how news about taxes signals subsequent realizations of tax rates. It is natural to pose this as a signal-extraction problem that faces both agents, who are interpreting the news, and the econometrician, who is trying to identify the latent news from observables. This emphasizes an aspect of the economic structure -information flows - that macroeconomists often do not explore.

Strong assumptions about information flows, like those typically made in DSGE models, can help to resolve the econometric difficulties that foresight presents. Once the information structure of the economy has been specified, a solution to the signal-extraction problem is available through the use of, for example, the Kalman filter. Of course, the solution is conditional on the specified information flows, an aspect of the economic structure about which economists rarely have well developed prior beliefs. That foresight poses a structural problem and not merely a statistical problem has not been widely appreciated, even in work that focuses on foresight of various kinds; it is also not readily resolved.

Fiscal foresight poses a formidable challenge because, as Leeper (1989) and Yang (2005) show, it generates an equilibrium with a nonfundamental representation. A nonfundamental representation is one in which the equilibrium time series contains a moving average component that is not invertible in current and past observables. ${ }^{3}$ Issues associated with nonfundamentalness were pointed out in the rational expectations econometrics literature by Hansen and Sargent $(1980,1991)$ and Lippi and Reichlin $(1993,1994)$ and recently emphasized by Fernandez-Villaverde, Rubio-Ramirez, Sargent, and Watson (2007). ${ }^{4}$ To the extent that fiscal foresight is an intrinsic feature of the tax policy process, conventional

\footnotetext{
${ }^{3}$ Throughout the paper, we use the terms "nonfundamental" and "noninvertible" interchangeably.

${ }^{4}$ A closely related line of work examines the conditions under which a finite-order VAR can adequately capture agents' information sets when state variables are excluded from the VAR system [for example, Cooley and Dwyer (1995), Fry and Pagan (2005), Kapetanios, Pagan, and Scott (2005), Giannone, Reichlin, and Sala (2006), Giannone and Reichlin (2006), Chung and Leeper (2007), Dungey and Fry (2007)]. This work argues that expanding the VAR to include important state variables can solve the invertibility problem. Faust, Rogers, Swanson, and Wright (2003) and Faust, Swanson, and Wright (2004) do not directly address non-invertibility, but they use high-frequency financial data to expand the econometrician's information set to aid in identifying monetary policy effects. Fiscal foresight is distinctive because data on the missing state variable - exogenous changes in anticipated future tax rates - are not readily available nor are they straightforward to collect.
} 
econometric work on fiscal policy ascribes to the econometrician an information set that is strictly smaller than the information set on which agents base their decisions.

This paper offers three contributions that are distinct from previous work on nonfundamental equilibria:

(1) It identifies an important practical instance - fiscal policy - that is likely to give rise to noninvertible equilibria and it offers some evidence that private agents possess and react to news about future tax changes.

(2) Rather than simply positing a nonfundamental driving process in an economic model, we obtain a nonfundamental equilibrium through the information flows implied by the government's technology for choosing tax rates (the government policy rule). The nonfundamentalness that arises from fiscal foresight is a natural by-product of the fact that agents' optimal intertemporal decisions discount future tax obligations. Although private agents discount tax rates in the usual way, they discount recent tax news more heavily than past news because with foresight the recent news informs about taxes in the more distant future. The econometrician, in contrast, discounts in the usual way, down weighting older news relative to recent news. Agents and the econometrician employ different discounting patterns because the econometrician's information set lags the agents'.

(3) We go beyond the binary test of invertibility proposed, for example, by FernandezVillaverde, Rubio-Ramirez, Sargent, and Watson (2007) to assess the quantitative importance of nonfundamentalness in a calibrated DSGE model drawn from the class of models being fit to data. We couch the quantitative assessment in terms of tax multipliers and show that conventional econometric methods, such as identified VARs, can produce wildly inaccurate inferences: multipliers can be estimated to be positive, negative, or zero and they can be five or more times too large over various forecast horizons. Within such a model we probe the sensitivity of such errors in inference to alternative assumptions of how news about taxes flows into the economy. Whereas Lippi and Reichlin (1993) argue that economic theory does not necessarily rule out nonfundamental representations, we show that for fiscal policy, plausible hypotheses about the flow of information about tax changes imply that fundamental representations cannot necessarily be ruled in.

This paper focuses exclusively on foresight about taxes, but misalignment of agents' and the econometrician's information sets, and the possibility of nonfundamental equilibrium representations, is a widespread problem in macroeconomics. A prominent example is Quah's (1990) resolution of Deaton's (1987) paradox; the resolution relies on agents forecasting future income using strictly more information than the econometrician does. FernandezVillaverde, Rubio-Ramirez, and Sargent (2005) contains several examples of DSGE models that in some regions of the parameter space exhibit an invertibility problem.

Nonfundamentalness is likely to present itself in several areas of research that are now receiving attention: news about future technological improvement [Beaudry and Portier (2006), Christiano, Ilut, Motto, and Rostagno (2007), Jaimovich and Sergio (2008), SchmittGrohe and Uribe (2008)]; foresight about large government spending run ups [Ramey (2007)]; recent moves by several inflation-targeting central banks - Norges Bank, Reserve Bank of New Zealand, Sveriges Riksbank - to publish paths of future policy interest rates [Holmsen, 
Qvigstad, and Roisland (2007), Blattner, Catenaro, Ehrmann, Strauch, and Turunen (2008), Laseen, Linde, and Svensson (2008)]. Any of these applications, when studied in a rational expectations model, would lend themselves to the type of analysis that we conduct. Our paper raises a warning flag about econometric work on these topics and calls for careful modeling of the information flows that give rise to economic foresight in general.

\section{Evidence of Fiscal Foresight}

Plenty of reduced-form and anecdotal evidence, mostly in the form of case studies of one or more tax episodes, suggests that private agents respond to expected changes in taxes. Reactions to tax foresight are most evident when policy changes are phased in, incorporate sunset provisions, or include a delay between enactment and effective dates.

Steigerwald and Stuart (1997) develop a residual-based test statistic, which allows comparison of prediction errors for econometric models under different assumptions about the period of tax foresight. By studying investment behavior around major tax legislation that altered corporate income tax rates, investment tax credits, or the deductions for depreciation allowances, Steigerwald and Stuart conclude that firms had 4.5-month foresight for tax changes in 1954, 1962, and 1981, and 16.5-month foresight for the tax reform of 1986.

In contrast to Steigerwald-Stuart, Poterba's (1988) study of consumption responses to tax announcements associated with legislation in 1964, 1968, 1975, 1981, and 1986, finds little evidence of anticipatory behavior. He dates expectational changes as occurring the month the legislation passes Congress. Poterba regards his findings as "tentative" because his event study "is likely to have relatively low power against the alternative hypothesis that consumers gradually revise their expectations of future tax policy and adjust consumption accordingly" [p. 416].

The possibility that fiscal foresight can produce a "purely anticipatory recession" was first put forth by Branson, Fraga, and Johnson (1986) in an exploration of President Reagan's tax cuts. The Economic Recovery Tax Act, enacted in August 1981, announced a three-stage tax cut to be phased in from 1982 to 1984. Branson, Fraga, and Johnson argue that in an open-economy IS-LM model, anticipated tax cuts can reconcile three salient features of the U.S. macro experience of the early 1980s: an inverted and steep real yield curve, real appreciation of the dollar, and a severe recession - all of which occurred in 1981 and 1982, before the tax cuts were fully realized. Mertens and Ravn (2008) make a similar argument using a modern DSGE model and the time series on forecasted tax changes that Romer and Romer (2007b) compiled.

The Tax Reform Act of 1986 offered public finance economists a rich laboratory in which to test hypotheses that economic agents may respond to news about tax changes before the changes are effective. The legislation, which was enacted in October 1986, repealed the capital gains exclusion from ordinary income, raising the maximum capital gains tax rate beginning in 1987 from an effective rate of 20 percent to 28 percent. During the lag between enactment and effective dates, capital gains realizations jumped from $\$ 172$ billion in 1985 to $\$ 328$ billion in 1986 in anticipation of the tax hike [Congressional Budget Office (2002, Table 1, p. 3)]. 


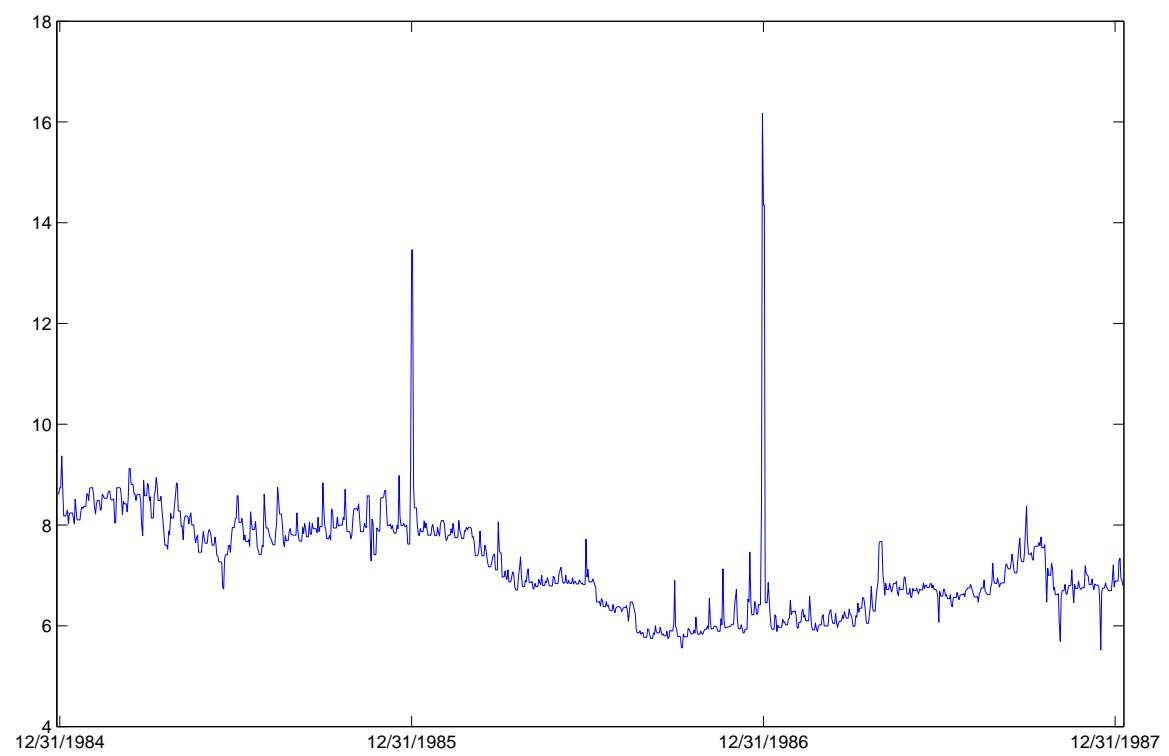

Figure 1. Daily Federal Funds Rate

Auerbach and Slemrod (1997) thoroughly review the economic effects of the 1986 reform. They also point out the jump in long-term capital gains realizations that predated the effective date of the reform [see also Burman, Clausing, and O'Hare (1994)]. Auerbach and Slemrod argue that the 1986 Act "established once and for all that the timing of capital gains realizations behavior can be enormously sensitive to anticipated changes in the rate of taxation" [p. 605]. The act also reduced marginal corporate tax rates from a maximum of 46 percent in 1986 to a maximum of 34 percent over 1987 and 1988. Scholes, Willson, and Wolfson (1992) find that the corporate tax rate reduction induced firms to act in anticipation to defer revenue recognition or accelerate expense recognition.

Figure 1 documents two instances in which anticipations of the tax code changes associated with the Tax Reform Act of 1986 spilled over to affect monetary policy behavior. The figure plots the daily federal funds rate from December 29, 1984 through January 9, 1988. At the end of both 1985 and 1986, the daily federal funds rate spiked as traders shifted their portfolios to get ahead of expected restrictive tax legislation. On December 31, 1985 the funds rate rose almost 4.5 percentage points when, after the House of Representatives passed the legislation on December 17, traders placed higher probability that tax reform would take effect during 1986. As it happened, the bill was not enacted until October 22, 1986, to be effective on January 1, 1987. This is why the funds rate more than doubled on December 30, 1986, and remained high on the last day of 1986. Despite repeated injections of funds throughout the year, the trading desk at the New York Fed underestimated the extent to which money markets would react to foresight about tax policy changes [see Federal Reserve Bank of New York $(1986,1987)]$.

A well-documented example of behavior due to foresight underlies the controversy related to estimating the taxable income elasticity with respect to the tax hike for the high-income 
group that was embedded in the Omnibus Budget Reconciliation Act of 1993. Feldstein and Feenberg (1996) examine the changes in income and tax data from 1992 to 1993 and find a large taxable income elasticity for the high-income group. Their finding implies that an increase in the marginal tax rate has a strong negative effect on the tax base. Goolsbee (2000), on the other hand, finds this elasticity drops to 0.4 if the data are extended to 1995. As the share of time-shiftable compensation (such as one-time bonuses, exercising stock options, and so forth) rose dramatically with income from 1991 to 1992, the contrasting estimates of a high short-run and low long-run elasticity arise because high-income taxpayers in 1992 acted upon their foresight about anticipated higher income tax rates.

House and Shapiro (2006) use a neoclassical growth model with fiscal foresight to calibrate the macroeconomic effects of President Bush's phased-in cuts in capital and labor tax rates beginning in 2001. They argue that the slow recovery from the 2001 recession, especially in the job market, can be attributed to the law's phasing-in provisions, which created incentives for workers and firms to delay production. Elimination of the phase-ins in 2003, moreover, accounted for about half of the rebound in GDP in the middle of 2003. In recent work, House and Shapiro (2008) estimate that investment in qualified types of capital - capital with a tax recovery period of up to 20 years - rose in anticipation of the bonus depreciation provision of the law. Investment began to rise after the House of Representatives passed the bill in October 2001, before President Bush signed the legislation in March 2002.

Evidence of the impacts of fiscal foresight extends well beyond a single piece of legislation. Yang (2007) compares responses to a typical tax innovation from VAR systems with and without interest rates and prices. She finds that adding the three-month Treasury bill rate and the GDP price deflator (or commodity prices) to a VAR substantially reduces the responses of labor, investment, and output to a tax innovation. Since financial markets tend to be relatively sensitive to news in the economy, the result is consistent with the interpretation that information contained in financial variables reflects agents' knowledge of future tax policy changes. Sims (1988) finds similar results for government spending multipliers.

Fiscal foresight may also apply to government spending: anticipated shifts in spending may trigger changes in economic behavior before the spending shift is realized. Recent efforts by Ramey (2007) to reconcile the discrepancies in the effects of government spending using the narrative approach based on war dummies and VAR approaches lead her to conclude that the VAR-based innovations are indeed anticipated. ${ }^{5}$ Since the war dates are identified based on the timing when the media reported future defense buildups, the news reports predate the actual rises in defense spending. Ramey finds that the war dates Granger-cause defense spending and aggregate government spending, but not vice versa. This supports the existence of foresight about government spending policy.

There is a line of work that is often interpreted as providing evidence that consumers do not adjust savings in response to anticipated changes in taxes and that, therefore, fiscal foresight is unlikely to be important in time series data. The work, which uses natural tax experiments to test the permanent income hypothesis, finds that agents respond strongly to predictable changes in tax liabilities and to current disposable income, a result that is taken

\footnotetext{
${ }^{5}$ See Ramey and Shapiro (1998) and Edelberg, Eichenbaum, and Fisher (1999) for empirical analysis of the dynamic impacts of war dummies.
} 
as evidence against the hypothesis. ${ }^{6}$ Because these papers focus on responses at the time of or after the implementation of the policy change, they are silent about how behavior changes during the foresight period. In fact, in a neoclassical growth model, where the permanent income hypothesis holds, consumption responds both at the time that news about a future change in capital or labor tax rates arrives and after the implementation of the tax rate change [see Yang (2005)].

The evidence of fiscal foresight recounted here, although not decisive, does support the view that some adjustment in behavior occurs before tax changes are implemented. The evidence, however, is typically rather casual, relying on case studies, and it is often not tightly connected to theory. We now turn to an illustrative model in which some of the econometric implications of fiscal foresight can be derived explicitly.

\section{Analytical Example}

In this section, we introduce fiscal foresight into a simple economic environment so that the econometric issues can be exposited analytically. The results and conclusions reached in this section and the next extend to more general setups, as discussed in section 5 .

Consider a standard growth model with log preferences, inelastic labor supply, and complete depreciation of capital. A proportional tax is levied against income. The equilibrium conditions are well known and given by

$$
\begin{gathered}
\frac{1}{C_{t}}=\alpha \beta E_{t}\left(1-\tau_{t+1}\right) \frac{1}{C_{t+1}} \frac{Y_{t+1}}{K_{t}} \\
C_{t}+K_{t}=Y_{t}=A_{t} K_{t-1}^{\alpha}
\end{gathered}
$$

where $C_{t}, K_{t}$, and $Y_{t}$ denote time- $t$ consumption, capital, and output, respectively, and $\left\{A_{t}\right\}$ is an exogenous technology shock. As usual, $0<\alpha<1$ and $0<\beta<1$. The government sets the tax rate according to a time-invariant rule and then adjusts lump-sum transfers to satisfy the constraint, $T_{t}=\tau_{t} Y_{t}$. Government spending is identically zero.

After log linearizing equations (1)-(2), the equilibrium is characterized by a second-order difference equation in capital

$$
E_{t} k_{t+1}-\left(\theta^{-1}+\alpha\right) k_{t}+\alpha \theta^{-1} k_{t-1}=E_{t}\left[a_{t+1}-\theta^{-1} a_{t}\right]+\left\{\theta^{-1}(1-\theta)\left(\frac{\tau}{1-\tau}\right)\right\} E_{t} \hat{\tau}_{t+1} .
$$

where $\theta=\alpha \beta(1-\tau)$ is a particularly important constant in the analysis and $0 \leq \tau<1$ is the steady state tax rate. The solution to (3) satisfies the well-known saddlepath property

\footnotetext{
${ }^{6}$ Shapiro and Slemrod (1995) use survey data to evaluate consumption responses to reductions in the income tax withholding as ordered by President Bush in early 1992. Parker (1999) studies withholding changes in Social Security taxes using sample drawn from 1980 and 1993 and Souleles (1999) studies changes to the receipts of tax refunds based on sample drawing from 1980 to 1991 . Souleles (2002) examines the consumption effect in response to withholding changes due to the pre-announced, phase-II income tax rate cuts in the Economic Recovery Tax Act. Johnson, Parker, and Souleles (2004) study President Bush's tax rebate in 2001. In an earlier study, very much in the spirit of this line of work, Poterba and Summers (1987) finds a failure of Ricardian equivalence, but acknowledge that their analysis is uninformative about the effects of fiscal foresight.
} 
and is given by

$$
k_{t}=\alpha k_{t-1}+a_{t}-(1-\theta)\left(\frac{\tau}{1-\tau}\right) \sum_{i=0}^{\infty} \theta^{i} E_{t} \hat{\tau}_{t+i+1} .
$$

Equilibrium investment depends negatively on the expected discounted present value of future tax rates, a well-known result [Lucas (1976), Abel (1982), Judd (1985), Auerbach (1989)]. Of course, more distant tax rates are discounted relative to more recent rates.

To model foresight, we must specify how news about taxes signals future tax rates. For many of the points we wish to make, it suffices to assume that tax information flows take a particularly simple form: agents at $t$ receive a signal that tells them exactly what tax rate they will face in period $t+q$. The tax rule is $\tau_{t}=\bar{\tau} e^{\varepsilon_{\tau, t-q}}$, or in log-linearized form ${ }^{7}$

$$
\hat{\tau}_{t}=\varepsilon_{\tau, t-q}
$$

where $\hat{\tau}$ denotes percentage deviations of the tax rate from its steady state value. ${ }^{8}$ We assume the technology and tax shocks are i.i.d. and the representative agent's information set at date $t$ consists of variables dated $t$ and earlier, including the shocks, $\left\{\varepsilon_{A, t}, \varepsilon_{\tau, t}\right\}$. Given the tax rule in (5), this implies that the agent at $t$ has (in this case, perfect) knowledge of $\left\{\hat{\tau}_{t+q}, \hat{\tau}_{t+q-1}, \ldots\right\}$.

It is useful to use the information flows in the tax rule to solve for expected tax rates in (4) for various degrees of fiscal foresight.

$q=0$ implies:

$$
k_{t}=\alpha k_{t-1}+\varepsilon_{A, t}
$$

$q=1$ implies:

$$
k_{t}=\alpha k_{t-1}+\varepsilon_{A, t}-(1-\theta)\left(\frac{\tau}{1-\tau}\right) \varepsilon_{\tau, t}
$$

$q=2$ implies:

$$
k_{t}=\alpha k_{t-1}+\varepsilon_{A, t}-(1-\theta)\left(\frac{\tau}{1-\tau}\right)\left\{\varepsilon_{\tau, t-1}+\theta \varepsilon_{\tau, t}\right\}
$$

$q=3$ implies:

$$
k_{t}=\alpha k_{t-1}+\varepsilon_{A, t}-(1-\theta)\left(\frac{\tau}{1-\tau}\right)\left\{\varepsilon_{\tau, t-2}+\theta \varepsilon_{\tau, t-1}+\theta^{2} \varepsilon_{\tau, t}\right\}
$$

If there is no foresight, $q=0$, we get the usual result that i.i.d. shocks to tax rates have no effect on capital accumulation. When there is some degree of tax foresight $(q>0)$, we obtain the unusual implication that even serially uncorrelated tax hikes reduce capital accumulation.

In this model with inelastic labor supply, i.i.d. tax shocks should not affect capital accumulation. As expression (7) makes clear, when there is one period of foresight, tax shocks

\footnotetext{
${ }^{7}$ We will assume a bounded support on $\varepsilon_{\tau}$ for each specification of the tax rule to ensure the realizations are bounded between 0 and 1 .

${ }^{8}$ Jaimovich and Sergio (2008) assume an analogous process for the arrival of news about total factor productivity or investment-specific shocks.
} 
appear to affect capital contemporaneously. Moving average terms and, therefore, potential invertibility problems appear to arise only when the foresight horizon is greater than one period. This result is not general and stems from the assumption of fixed labor. When labor choice is elastic, even one period of foresight can produce an equilibrium with a noninvertible moving average component.

An interesting, though seemingly perverse, implication of (8) and (9) is that more recent news is discounted (by $\theta=\alpha \beta(1-\tau)<1$ ) relative to older news. This is because with twoquarter foresight, $\varepsilon_{\tau, t-1}$ affects $\hat{\tau}_{t+1}$, while $\varepsilon_{\tau, t}$ affects $\hat{\tau}_{t+2}$, so the news that affects tax rates farther into the future receives the heaviest discount. Tax rates are discounted in the usual way, while tax news is discounted in reverse order. We now explore the broader ramifications of this discounting result.

\section{The ECOnOMEtrics of Foresight}

This section explores the question: What erroneous conclusions might be drawn by an econometrician who does not explicitly model tax foresight and proceeds with conventional econometric analyses, such as identified VARs? ${ }^{9}$

4.1. Misalignment of Information Sets and Improper Discounting. With fiscal foresight, the information set of private agents may be larger than the econometrician's information set. The Wold representation theorem tells us that the econometrician's information set from estimating a VAR will be the sigma algebra generated by current and past observable variables. In the analytical example, foresight implies that agents will observe tax news before the tax rates are realized. Information sets of private agents will not coincide with the information generated by observable variables, which the econometrician possesses.

We begin with the case in which the econometrician is well informed, observing the technology shock exactly. Suppose that agents have two-quarter foresight and the econometrician estimates a VAR with current and past capital and technology, $\left\{k_{t-j}, a_{t-j}\right\}_{j=0}^{\infty}$,

$$
\begin{aligned}
{\left[\begin{array}{l}
a_{t} \\
k_{t}
\end{array}\right]=} & {\left[\begin{array}{cc}
0 & 1 \\
\frac{-\kappa(L+\theta)}{1-\alpha L} & \frac{1}{1-\alpha L}
\end{array}\right]\left[\begin{array}{l}
\varepsilon_{\tau, t} \\
\varepsilon_{A, t}
\end{array}\right] } \\
& \mathbf{y}_{t}=\mathcal{M}(L) \boldsymbol{\epsilon}_{t},
\end{aligned}
$$

where $\kappa=(1-\theta)(\tau /(1-\tau)), \theta=\alpha \beta(1-\tau)$ and $L$ is a lag operator (i.e., $\left.L^{s} x_{t}=x_{t-s}\right)$. If this system is invertible in nonnegative powers of $L$, then $\boldsymbol{\epsilon}_{t}$ may be obtained as a squaresummable linear combination of current and past $\mathbf{y}_{t}$. This suggests that knowledge of past and present $\mathbf{y}$ is equivalent to knowledge of past and present $\boldsymbol{\epsilon}$, and forecast errors generated by the econometrician's VAR will coincide with the agents'. ${ }^{10}$ A necessary condition for (10) to be a fundamental Wold representation is that the determinant of $\mathcal{M}(z)$ be analytic with no zeros inside the open unit disk. ${ }^{11}$ By direct calculation, $\operatorname{det} \mathcal{M}(z)=\frac{\kappa}{1-\alpha z}(z+\theta)$, so this representation has a zero inside the unit circle $($ at $z=-\theta)$. Fiscal foresight implies the

\footnotetext{
${ }^{9}$ Much of the analysis that follows draws on Hansen and Sargent (1991).

${ }^{10}$ More specifically, the Hilbert space generated by $\left\{\mathbf{y}_{t-j}\right\}_{j=0}^{\infty}$ is equivalent (in mean-square norm) to the Hilbert space generated by $\left\{\boldsymbol{\epsilon}_{t-j}\right\}_{j=0}^{\infty}$.

${ }^{11}$ This assumes that "noninvertible" means a root inside the unit circle.
} 
information set generated by $\left\{\mathbf{y}_{t}, \mathbf{y}_{t-1}, \mathbf{y}_{t-2}, \ldots\right\}$ is smaller than the information set generated by $\left\{\boldsymbol{\epsilon}_{t}, \boldsymbol{\epsilon}_{t-1}, \boldsymbol{\epsilon}_{t-2}, \ldots\right\}$.

It is useful to think about this invertibility condition for each shock process individually. By assumption the econometrician directly observes current and past technology shocks $\left\{\varepsilon_{A, t}, \varepsilon_{A, t-1}, \ldots\right\}$. Conditioning on current and past capital, however, will not reveal current and past tax shocks. The reason is that while the technology process is an invertible representation, the process for capital is not. The solution for capital with two-quarter foresight is given by

$$
(1-\alpha L) k_{t}=-\kappa(L+\theta) \varepsilon_{\tau, t}
$$

Invertibility of the stochastic process in current and past $k_{t}$ requires $|\theta|>1$, so that

$$
\left[\frac{1-\alpha L}{1+\theta^{-1} L}\right] k_{t}=-\kappa \theta \varepsilon_{\tau, t}
$$

is a convergent sequence. Because $\theta=\alpha \beta(1-\tau)<1$, the process is not invertible in current and past capital. Of course, the representation is invertible in current and future capital:

$$
\begin{gathered}
{\left[\frac{1-\alpha L}{1+\theta L^{-1}}\right] k_{t}=-\kappa \varepsilon_{\tau, t-1}} \\
k_{t}=\left(\alpha^{-1}+\theta\right) k_{t+1}-\theta\left(\alpha^{-1}+\theta\right) k_{t+2}+\theta^{2}\left(\alpha^{-1}+\theta\right) k_{t+3}-\cdots+\alpha^{-1} \kappa \varepsilon_{\tau, t} .
\end{gathered}
$$

In this VAR setting, the only way that the econometrician can recover the fiscal news seen by agents at time $t$ is if the econometrician has knowledge of future variables. ${ }^{12}$

Foresight concerning fiscal policy introduces a noninvertible moving average representation into the equilibrium. This non-invertibility implies the econometrician will not be able to condition on current and past $\varepsilon_{\tau, t}$. In order to determine the econometrician's information set, we need to derive the one-step-ahead forecast errors associated with predicting $\mathbf{y}_{t}$ conditional only on its past values. This is achieved by flipping the root of the moving average representation from inside the unit circle to outside the unit circle via the Blaschke factor, $[(L+\theta) /(1+\theta L)]$. The Wold representation for system (10) is given by

$$
\begin{aligned}
& {\left[\begin{array}{l}
a_{t} \\
k_{t}
\end{array}\right]=\underbrace{\left[\begin{array}{cc}
0 & 1 \\
\frac{-\kappa(L+\theta)}{1-\alpha L} & \frac{1}{1-\alpha L}
\end{array}\right]\left[\begin{array}{cc}
\frac{1+\theta L}{L+\theta} & 0 \\
0 & 1
\end{array}\right]} \underbrace{\left[\begin{array}{cc}
\frac{L+\theta}{1+\theta L} & 0 \\
0 & 1
\end{array}\right]\left[\begin{array}{l}
\varepsilon_{\tau, t} \\
\varepsilon_{A, t}
\end{array}\right]}} \\
& \mathbf{y}_{t}=\mathcal{M}^{*}(L) \quad \boldsymbol{\epsilon}_{t}^{*} .
\end{aligned}
$$

which yields the representation for capital as

$$
\begin{aligned}
(1-\alpha L) k_{t} & =\underbrace{-\kappa(L+\theta)\left[\frac{1+\theta L}{L+\theta}\right]}_{-\kappa(1+\theta L)} \underbrace{\left[\frac{L+\theta}{1+\theta L}\right] \varepsilon_{\tau, t}}_{\varepsilon_{\tau, t}^{*}} \\
& =-(1-\theta)\left(\frac{\tau}{1-\tau}\right)\left\{\theta \varepsilon_{\tau, t-1}^{*}+\varepsilon_{\tau, t}^{*}\right\} .
\end{aligned}
$$

Note that by observing current and past capital, the econometrician recovers current and past $\varepsilon_{\tau}^{*}$, which are not the news that private agents observe, $\varepsilon_{\tau}$. The econometrician's innovations

\footnotetext{
${ }^{12}$ Instrumental variables have been employed to deal with fiscal foresight [Blanchard and Perotti (2002)]. This representation demonstrates the properties necessary for valid instruments for foresight in this model.
} 
are the statistical shocks of the VAR, which turn out to represent information that is mostly "old news" to the agents of the economy. To see this more clearly note that

$$
\begin{aligned}
\varepsilon_{\tau, t}^{*} & =\left[\frac{L+\theta}{1+\theta L}\right] \varepsilon_{\tau, t}=(L+\theta) \sum_{j=0}^{\infty}-\theta^{j} \varepsilon_{\tau, t-j} \\
& =\theta \varepsilon_{\tau, t}+\left(1-\theta^{2}\right) \varepsilon_{\tau, t-1}-\theta\left(1-\theta^{2}\right) \varepsilon_{\tau, t-2}+\theta^{2}\left(1-\theta^{2}\right) \varepsilon_{\tau, t-3}+\cdots
\end{aligned}
$$

The mapping in (14) shows that what the econometrician believes to be the tax innovation at time $t, \varepsilon_{t}^{*}$, is actually a discounted sum of the tax news observed by the agents at date $t$ and earlier.

An important implication is that the econometrician who ignores foresight will discount the innovations incorrectly. Comparing (13) with (8), according to the econometrician's VAR, yesterday's innovation has less effect than today's innovation (note the terms $\theta \varepsilon_{\tau, t-1}^{*}+\varepsilon_{\tau, t}^{*}$ in (13)). Agents with foresight, in contrast, discount news according to $\varepsilon_{\tau, t-1}+\theta \varepsilon_{\tau, t}$ because yesterday's news has a larger effect on capital accumulation than today's news. Differences in discounting patterns applied by the econometrician and the agents lead to a variety of econometric problems.

Mapping (14) also reveals that an equilibrium might fail to be invertible $-\theta<1-$ yet the noninvertibility may be quantitatively unimportant. Suppose $\theta$ is just below 1 . Then, according to $(14), \varepsilon_{\tau, t}^{*}$ will be "close enough" to $\varepsilon_{\tau, t}$ that the econometrician's estimates of tax effects will not be far wrong. Section 5 examines the quantitative importance of noninvertibility in a calibrated DSGE model.

4.2. Econometric Implications. By employing VAR analysis and not modeling foresight, the econometrician has unknowingly conditioned on a smaller information set and misspecified the true dynamics of the equilibrium. Not surprisingly, the consequence of this misspecification is that inference provided by VARs may be quite misleading. The size of the approximation error depends upon several factors - the complexity of the tax rule (5), the conditioning variables in the VAR, the structural parameters, the degree of foresight, and so forth. We show below how these factors confound the analysis in the present setting.

Impulse response functions are a widely used tool for conveying how agents dynamically respond to innovations, but response functions based upon the econometrician's information set $\left\{\varepsilon_{\tau, t}^{*}\right\}$ will not capture these responses. Consider the response functions generated by (10) and (12). Figure 2 plots the responses of capital and output assuming two-quarter foresight (setting $\alpha=0.36, \beta=0.99, \tau=0.25$ ). With foresight, agents know exactly when the innovation in fiscal policy is going to translate into changes in the tax rate. This creates the sharp decline in capital one quarter after the shock and in output two quarters out, as the dotted-dashed lines indicate. The econometrician's VAR, on the other hand, discounts the innovations incorrectly and gives a very different response to the tax shock. According to the econometrician, the biggest decline in capital will occur on impact, suggesting that foresight does not exist (solid lines). The difference between the response functions can be quite dramatic, especially at short horizons. Note that the drop in output for the econometrician's VAR is nearly four times as large as the true response one quarter after the innovation. 


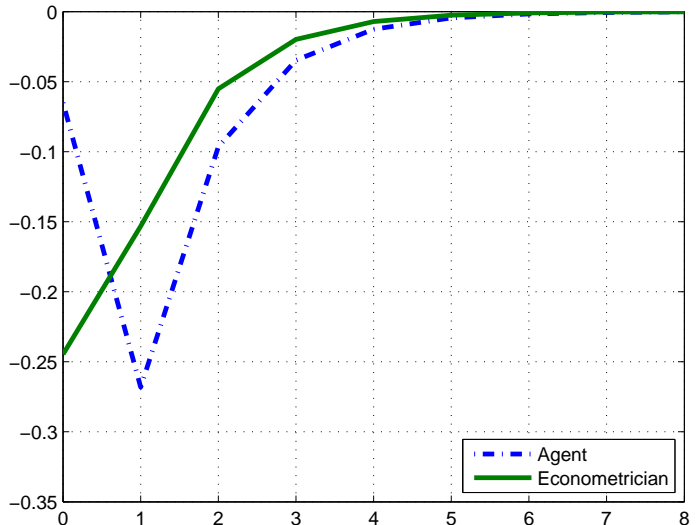

Figure 2a: Response of $K$

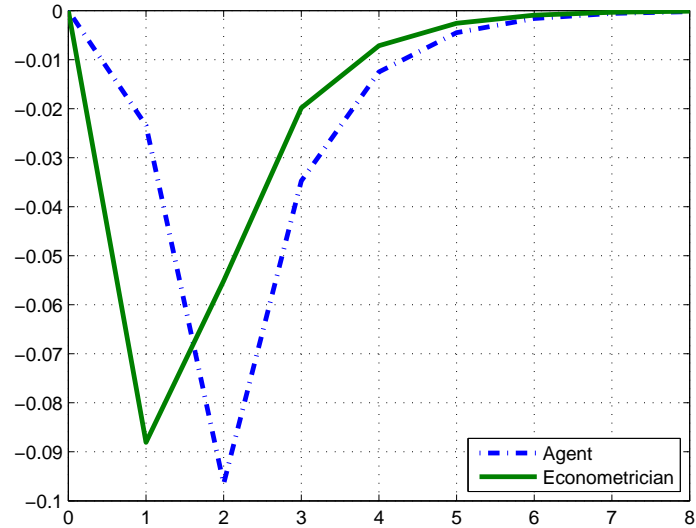

Figure 2b: Response of $Y$

Figure 2. Responses of Capital and Output to Tax Increase. VAR system includes $\left(a_{t}, k_{t}\right)^{\prime}$ with $\alpha=0.36, \beta=0.99, \tau=0.25$

Figure 2 shows that the econometrician will infer that the tax shock is unanticipated. Obviously, not all shocks that affect fiscal policy will be knowable several quarters in advance. Consider a tax rate process, $\hat{\tau}_{t}=e_{\tau, t}^{u}+\varepsilon_{\tau, t-q}$, that allows for shocks that are anticipated several quarters in advance $\left(\varepsilon_{\tau}\right)$ and for surprises that are unanticipated $\left(e_{\tau}^{u}\right)$ at time $t{ }^{13}$ If these shocks are orthogonal at all leads and lags, then the equilibrium dynamics of (3) will not change because i.i.d. tax shocks will not alter the dynamics of capital. The econometrician, who does not account for fiscal foresight and proceeds to estimate (12), will attribute all of the dynamics associated with the anticipated component of the tax rate to the unanticipated component. This suggests that researchers interested in the dynamic effects of fiscal policywhether the interest is in anticipated or unanticipated changes in policy-must explicitly account for foresight in order to avoid spurious conclusions.

Fiscal foresight becomes even more pernicious if we make the more plausible assumption that the econometrician does not observe technology shocks and, therefore, cannot condition on $\left\{\varepsilon_{A, t}, \varepsilon_{A, t-1}, \ldots\right\}$. It is more natural for the econometrician to condition on observable taxes (or some function of taxes, such as revenues), rather than the technology process. Consider the case with two-quarter foresight and suppose the econometrician estimates the following VAR

$$
\begin{gathered}
{\left[\begin{array}{l}
\hat{\tau}_{t} \\
k_{t}
\end{array}\right]=\frac{\left[\begin{array}{cc}
L^{2} & 0 \\
\frac{-\kappa(L+\theta)}{1-\alpha L} & \frac{1}{1-\alpha L}
\end{array}\right]\left[\begin{array}{c}
\varepsilon_{\tau, t} \\
\varepsilon_{A, t}
\end{array}\right]}{\mathbf{x}_{t}=\mathcal{H}(L) \boldsymbol{\epsilon}_{t} .}}
\end{gathered}
$$

As in the previous case, foresight creates a zero inside the unit circle (now at $z=0$ ), implying that the information set generated by $\left\{\mathbf{x}_{t}, \mathbf{x}_{t-1}, \mathbf{x}_{t-2}, \ldots\right\}$ is smaller than the information set generated by $\left\{\boldsymbol{\epsilon}_{t}, \boldsymbol{\epsilon}_{t-1}, \boldsymbol{\epsilon}_{t-2}, \ldots\right\}$. The corresponding Wold representation for (15) is derived

\footnotetext{
${ }^{13}$ Christiano, Ilut, Motto, and Rostagno (2007) posit a process like this for a technology shock and interpret realizations of the $\varepsilon$ terms as news.
} 


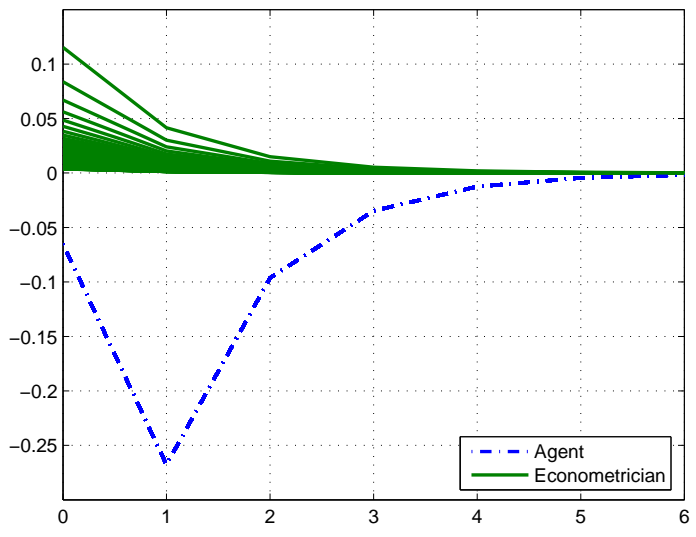

Figure 3a: Response of $K$ to Tax Increase $\sigma_{\tau}^{2}=1, \sigma_{a}^{2}=[0.01,1]$

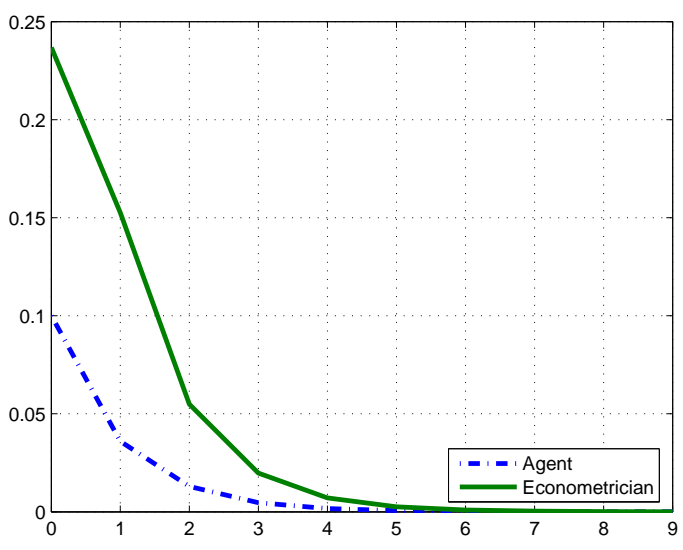

Figure 3b: Response of $K$ to Technology Increase $\sigma_{\tau}^{2}=1, \sigma_{a}^{2}=0.01$

Figure 3. Responses of Capital. VAR system includes $\left(\tau_{t}, k_{t}\right)^{\prime}$

by flipping the zeroes outside the unit circle as in the previous example,

$$
\begin{aligned}
& {\left[\begin{array}{l}
\hat{\tau}_{t} \\
k_{t}
\end{array}\right]=\underbrace{\left[\begin{array}{cc}
L^{2} & 0 \\
\frac{-k(L+\theta)}{1-\alpha L} & \frac{1}{1-\alpha L}
\end{array}\right] W \mathcal{B}(L) \tilde{W} \mathcal{B}(L)} \underbrace{\mathcal{B}\left(L^{-1}\right) \tilde{W}^{\prime} \mathcal{B}\left(L^{-1}\right) W^{\prime}\left[\begin{array}{c}
\varepsilon_{\tau, t} \\
\varepsilon_{A, t}
\end{array}\right]}} \\
& \mathbf{x}_{t}=\quad \mathcal{H}^{*}(L) \\
& \epsilon_{t}^{*}
\end{aligned}
$$

where

$$
W=\left[\begin{array}{ll}
\frac{1}{\sqrt{1+(\theta \kappa)^{2}}} & \frac{-\kappa \theta}{\sqrt{1+(\theta \kappa)^{2}}} \\
\frac{\kappa \theta}{\sqrt{1+(\theta \kappa)^{2}}} & \frac{1}{\sqrt{1+(\theta \kappa)^{2}}}
\end{array}\right], \tilde{W}=\left[\begin{array}{cc}
\Delta\left(1+\kappa^{2} \theta^{2}\right) & -\Delta \kappa \\
\Delta \kappa & \Delta\left(1+\kappa^{2} \theta^{2}\right)
\end{array}\right], \mathcal{B}(L)=\left[\begin{array}{cc}
L^{-1} & 0 \\
0 & 1
\end{array}\right]
$$

and $\Delta=\left[\left(1+\kappa^{2} \theta^{2}\right)^{2}+\kappa^{2}\right]^{-1 / 2}$. In this case, the orthonormal $W$ matrix must be employed to ensure the representation remains causal (i.e., preserves the assumption that the econometrician does not observe future values of the variables).

Now the econometric problems are more severe. First, the econometrician who proceeds with VAR analysis using (16) will likely obtain an impulse response function in which foresight does not appear to exist in the data. Figure 3a depicts the response of capital to a tax increase for the agent and econometrician (dotted-dashed line) as the variance of the technology shock varies from 0.01 to 1 (using the calibration $\alpha=0.36, \beta=0.99, \tau=0.25$ ). This figure shows that conditioning on the econometrician's information set the path of capital is flat when $\sigma_{a}^{2}=\sigma_{\tau}^{2}=1$. In theory, unanticipated i.i.d. capital tax shocks have no effects on the economy. Based on the flat response of capital, an econometrician will then infer that the effects of fiscal policy are limited to unanticipated components only. By not modeling foresight, one may achieve a "self-fulfilling prophesy" and wrongly conclude that foresight is not an issue.

Second, as the variance of the tax shock increases relative to the technology shock, the errors associated with foresight become more pronounced. Figure 3a shows that the initial response of $K$ to a one standard deviation increase in the tax shock increases from 0 to 
0.12 as $\sigma_{a}^{2}$ varies from 1 to 0.01 , respectively, so that an anticipated tax increase could be estimated to have no effect or a positive effect on capital and output.

Existing empirical work reports a diverse set of inferences about the effects of an anticipated tax increase on output, ranging from little or no effect to contractionary to expansionary. Figures $2 \mathrm{a}$ and $3 \mathrm{a}$ demonstrate that even this simple model can deliver the diverse set of results found in the empirical literature. In our case an anticipated tax increase always lowers capital and output. The different solid lines in the figures arise from confronting the econometrician with different signal-extraction problems. This suggests that foresight and how it is handled econometrically is a leading cause of the diverse results.

Third, the statistical shocks recovered by the VAR analysis are now linear combinations of both technology and tax shocks. From (16), the statistical shocks can be written as

$$
\varepsilon_{\tau, t}^{*}=a_{1} \varepsilon_{\tau, t-2}-a_{2} \varepsilon_{\tau, t-1}+a_{3} \varepsilon_{A, t-2}+a_{4} \varepsilon_{A, t-1}, \quad \varepsilon_{A, t}^{*}=-a_{4} \varepsilon_{\tau, t-1}-a_{3} \varepsilon_{\tau, t}-a_{2} \varepsilon_{A, t-1}+a_{1} \varepsilon_{A, t}
$$

where the $a$ 's are complicated functions of $\alpha, \beta$, and $\tau$. The econometrician will not only misinterpret the response to a tax shock but also the response to a technology shock. Figure $3 \mathrm{~b}$ demonstrates that the econometrician would infer a very large and persistent response of capital to a technology shock (solid line), when in fact the true dynamics are relatively small (dotted-dashed line). Comparing (17) with (14), one sees that the statistical shocks generated by (16) are not convolutions of the entire history of the structural shocks but only depend upon structural shocks dated $t-2$ and earlier. This is due entirely to the simple tax rule $\left(\hat{\tau}_{t}=\varepsilon_{\tau, t-2}\right)$. As the model and information flows become more realistic, this problem can become more severe. This example has a key message: foresight impinges on the econometrician's ability to correctly identify all shocks in the VAR.

Finally, as also emphasized by Hansen and Sargent (1991), variance decompositions in this environment can lead to spurious conclusions. ${ }^{14}$ Let

$$
E\left(\mathbf{x}_{t}-E_{t-j}^{*} \mathbf{x}_{t}\right)\left(\mathbf{x}_{t}-E_{t-j}^{*} \mathbf{x}_{t}\right)^{\prime}=\sum_{k=0}^{j-1} \mathcal{H}_{k}^{*} \Sigma^{*} \mathcal{H}_{k}^{*}
$$

denote the $j$-step ahead prediction error variance associated with the econometrician's information set, where $\Sigma^{*}$ is the variance-covariance matrix associated with $\left(\varepsilon_{\tau, t}^{*}, \varepsilon_{A, t}^{*}\right)^{\prime}$. Like impulse response functions, variance decompositions are derived using conditional expectations and hence the discrepancy in the information sets implies the coefficients generated by $\mathcal{H}^{*}(L)$ will lead to a misallocation of the variance across the structural shocks. Figure 3a suggests that the econometrician will treat the tax shock as nearly i.i.d. and infer that none of the variation in capital (and hence output) can be attributed to tax innovations. Consequently, all of the variation will be attributed to the technology shock. This result would continue to hold even if, in fact, the tax shock explained nearly all of the variation in capital (for example, by setting the variance of the technology shock, $\sigma_{A}^{2}$, arbitrarily small).

\footnotetext{
${ }^{14}$ This result holds even though the statistical shocks of the VAR remain uncorrelated. While the unconditional second moments of the VAR system remain the same due to the orthogonal nature of the Blaschke and $W$ matrices $\left(W W^{\prime}=\tilde{W} \tilde{W}^{\prime}=I\right.$ and $\left.\mathcal{B}(L) \mathcal{B}\left(L^{-1}\right)=I\right)$, the conditional moments will be different.
} 
4.3. Testing Economic Theory. An extension of the econometric implications is that tests of economic theory will also be misspecified. One important example pertaining to fiscal policy is the testing of the government's present-value constraint, which links the value of government debt to the expected discounted value of future primary surpluses. A widelyused approach to test present-value restrictions estimates a VAR with debt and surpluses and then tests for the cross-equation restrictions that the present-value condition imposes on the model [Campbell and Shiller (1987)]. As we have shown, fiscal foresight implies the VAR obtained by the econometrician will not yield the true dynamics and hence will not impose the correct cross-equation restrictions in testing the present value condition.

To see how foresight will lead to type I error in present-value tests, consider an endowment economy with lump sum taxes, a constant equilibrium real interest rate, and one-quarter foresight with respect to innovations in surpluses (receipts less expenditures net of interest payments on the government's debt). Taking expectations conditional on information at time $t-1$ of the government's flow budget constraint yields

$$
E\left(b_{t} \mid \Omega_{t-1}\right)=\beta^{-1} b_{t-1}-E\left(s_{t} \mid \Omega_{t-1}\right),
$$

where $s_{t}$ is the primary surplus, $b_{t}$ is one-period debt outstanding, and $\beta^{-1}=(1+r)$ is the constant gross rate of return between time $t$ and $t+1$. Fiscal sustainability is ensured by a policy rule that makes future surpluses rise with debt. Two exogenous disturbances - for revenues and spending - drive surpluses and agents have one period of foresight over both components of the surpluses. The policy rule is

$$
s_{t}=\gamma b_{t-1}+\frac{\varepsilon_{1, t-1}}{1-\rho_{1} L}+\frac{\varepsilon_{2, t-1}}{1-\rho_{2} L}
$$

where $\gamma$ is set to ensure that the agent's transversality condition for debt is satisfied and $0<\rho_{1}, \rho_{2}<1$ determine the serial correlation properties of the driving processes. The expectations are taken with respect to the agents' information set, which is assumed to be, $\Omega_{t-1}=\left\{\varepsilon_{1, t-j}, \varepsilon_{2, t-j}\right\}_{j=1}^{\infty}$. If this process holds for $t=0,1, \ldots T$, then imposing the transversality condition on government debt,

$$
\lim _{N \rightarrow \infty} \beta^{N} E\left(b_{t+N} \mid \Omega_{t-1}\right)=0
$$

implies the present-value restriction that the current value of outstanding debt equals future discounted surpluses,

$$
b_{t}=\sum_{j=1}^{\infty} \beta^{j} E\left(s_{t+j} \mid \Omega_{t-1}\right) .
$$

Following Hansen, Roberds, and Sargent (1991) and Roberds (1991), the cross-equation restrictions that satisfy (20) are given by

$$
\begin{gathered}
{\left[\begin{array}{l}
s_{t} \\
b_{t}
\end{array}\right]=\left[\begin{array}{cc}
L A(L) & L C(L) \\
\frac{\beta\left[L^{2} A(L)-\beta^{2} A(\beta)\right]}{L-\beta} & \frac{\beta\left[L^{2} C(L)-\beta^{2} C(\beta)\right]}{L-\beta}
\end{array}\right]\left[\begin{array}{l}
\varepsilon_{1, t} \\
\varepsilon_{2, t}
\end{array}\right]} \\
\mathbf{y}_{t}=\mathcal{P}(L) \mathbf{v}_{t}
\end{gathered}
$$

where $A(L)=\frac{\beta^{-1}-\gamma}{\left(1-\rho_{1} L\right)(1-\gamma L)}$, and $C(L)=\frac{\beta^{-1}-\gamma}{\left(1-\rho_{2} L\right)(1-\gamma L)}$. Two observations spring from (21). First, foresight implies that (21) is not an invertible representation (due to the zero at $L=0$ ). 
Second, the cross-equation restrictions imposed on the moving-average representation are nonlinear.

In light of the second observation, Campbell and Shiller (1987) derive the present-value restrictions on the VAR representation instead of the moving-average representation. This simplification makes the present-value constraint easy to test, as it amounts to restrictions on the coefficients of the VAR. Denote the invertible representation of $(21)$ by $\mathcal{P}^{*}(L)$ and write the corresponding VAR of $(21)$ as $^{15}$

$$
\begin{aligned}
{\left[\begin{array}{l}
s_{t} \\
b_{t}
\end{array}\right] } & =\mathcal{A}_{0}^{*-1} \mathcal{A}_{1}^{*}(L)\left[\begin{array}{l}
s_{t-1} \\
b_{t-1}
\end{array}\right]+\mathcal{A}_{0}^{*-1}\left[\begin{array}{l}
\varepsilon_{1 t}^{*} \\
\varepsilon_{2 t}^{*}
\end{array}\right] \\
& =\left[\begin{array}{ll}
a_{11} & a_{12} \\
a_{21} & a_{22}
\end{array}\right]\left[\begin{array}{l}
s_{t-1} \\
b_{t-1}
\end{array}\right]+\left[\begin{array}{l}
w_{1 t} \\
w_{2 t}
\end{array}\right] \\
\mathbf{y}_{t} & =A^{*} \mathbf{y}_{t-1}+\mathbf{w}_{t}
\end{aligned}
$$

Note that $\mathcal{A}^{*}(L)=\mathcal{P}(L)^{*-1}$, implying that the coefficients of the VAR will not yield the correct cross-equation restrictions implied by (21) when there is foresight. Campbell and Shiller (1987) show that the restrictions on the VAR coefficients implied by the presentvalue constraint are given by

$$
a_{11}+a_{21}=0, \quad a_{22}+a_{12}=\beta^{-1}
$$

With foresight, however, the restrictions given by (23) will not hold even though the presentvalue constraint is satisfied. The VAR estimates give

$$
a_{11}+a_{21}=\frac{\eta \rho_{1} \rho_{2} \beta A(\beta) C(\beta)}{\rho_{2} C(\beta)-\rho_{1} A(\beta)}, \quad a_{22}+a_{12}=\frac{A(\beta) \eta \rho_{2} \rho_{1}(C(\beta)-A(\beta))}{\beta\left(\rho_{2} C(\beta)-\rho_{1} A(\beta)\right)}
$$

where $\eta=\left(1+[A(\beta) C(\beta)]^{2}\right)^{-1 / 2}$. Therefore, the econometrician will incorrectly reject the null hypothesis that the present-value constraint holds.

Sargent (1981) calls for Granger (1969)-Sims (1972) causality tests to play a key role in helping the econometrician determine which variables properly belong in agents' information sets. For example, causality tests are commonly used to justify treating variables as exogenous for purposes of inference. Causality tests, however, are misspecified if agents have fiscal foresight. ${ }^{16}$ To see this more clearly, return to the analytical model of section 3 with one quarter of foresight and an i.i.d. tax rule. The (true) moving-average representation, on the left, and the (econometrician's) fundamental representation, on the right, in the variables $\left(\hat{\tau}_{t}, k_{t}\right)^{\prime}$ are given by

$$
\begin{aligned}
& {\left[\begin{array}{l}
\hat{\tau}_{t} \\
k_{t}
\end{array}\right]=\left[\begin{array}{cc}
L & 0 \\
-\frac{\kappa}{1-\alpha L} & \frac{1}{1-\alpha L}
\end{array}\right]\left[\begin{array}{l}
\varepsilon_{\tau, t} \\
\varepsilon_{A, t}
\end{array}\right] \quad=\left[\begin{array}{cc}
\delta & -\kappa \delta L \\
0 & {[\delta(1-\alpha L)]^{-1}}
\end{array}\right]\left[\begin{array}{c}
\delta\left(\varepsilon_{\tau, t-1}+\kappa \varepsilon_{A, t-1}\right) \\
\delta\left(-\varepsilon_{\tau, t}+\kappa \varepsilon_{A, t}\right)
\end{array}\right]} \\
& \mathbf{x}_{t}=\mathcal{D}(L) \boldsymbol{\epsilon}_{t} \quad=\mathcal{D}^{*}(L) \boldsymbol{\epsilon}_{t}^{*} .
\end{aligned}
$$

where $\delta=\left(1+\kappa^{2}\right)^{-1 / 2}$. Note that the zero appearing in the true MA will appear in the opposite off-diagonal in the econometrician's representation. By theorem 1 of Sims (1972), the econometrician's representation implies that $\hat{\tau}$ fails to Granger-cause $k$; in fact, $\hat{\tau}$ lies in

\footnotetext{
${ }^{15}$ Given the structure of the non-invertibility, the invertible representation is obtained as in (16).

${ }^{16}$ Leeper (1990) shows that fiscal foresight can imply that money growth Granger-causes deficits in an equilibrium in which deficits are systematically monetized.
} 
a proper subspace of $k$, and hence $k$ fails to Granger-cause $\hat{\tau}$. By not modeling foresight, the econometrician effectively reverses the Granger-causal ordering of the true dynamics.

\section{Quantitative Importance of Foresight}

This section examines the prevalence of noninvertibility in a more general setting and assesses the quantitative importance of foresight. In doing so, the section pushes the analysis forward in two fresh directions. First, we show that the modeling of information flows, which to this point has been rather crude, plays a critical role in determining whether the equilibrium is fundamental. When the equilibrium is nonfundamental, moreover, information flows influence the magnitude of the error that an econometrician who does not model foresight would make. Second, we conduct the analysis in a more complex DSGE model that is calibrated to U.S. time series [details in appendix A]. By adding many of the features that researchers commonly include in models that are fit to data, this section moves the analysis out of the realm of "toy" models and into the class of models now in use for practical policy analysis. We demonstrate that many of the frictions found in DSGE models tend to propagate the econometrician's errors. To assess the quantitative importance of foresight, we compute dynamic tax multipliers as estimated by an econometrician who fits an identified VAR and contrast those estimates to the true tax multipliers.

Two conclusions emerge. First, noninvertibility is a problem that is robust to substantial variations in model structures and information flows, so long as the information flows imply a sufficient degree of foresight. Second, the errors in inference from econometric estimates that do not confront foresight can be substantial.

5.1. Brief Model Description. As appendix A describes in detail, we extend the basic neoclassical growth model by adding elastic labor supply, variable utilization rates for capital, durable and non-durable consumption, habit formation in non-durable consumption, investment adjustment costs, deliberation costs for durable goods, and seven exogenous sources of random disturbance. Although this model abstracts from nominal considerations, it nonetheless includes many of the features that have proven to be important in fitting DSGE models to data [see, for example, Christiano, Eichenbaum, and Evans (2005), Smets and Wouters (2003, 2007), Adolfson, Laseen, Linde, and Villani (2007)].

Two features of the extended model aim to reflect the type of signal-extraction problem that agents actually face: endogeneity of tax policy and the gradual arrival of news about tax changes. We incorporate both automatic stabilizers and a systematic adjustment of taxes to the state of government debt, which relax the assumption of exogenous tax policy in the analytical example. To move away from perfect foresight, news about tax policy changes at time $t$ is revealed gradually beginning at $t-4, t-3, \ldots$, up to $t$. In log-linearized forms, labor and capital income tax rates are

$$
\hat{\tau}_{t}^{i}=\rho_{i} \hat{\tau}_{t-1}^{i}+q_{i} \hat{s}_{t-1}^{B}+\mu_{i} \hat{Y}_{t}+\sum_{j=0}^{4} \phi_{j} \varepsilon_{i, t-j}
$$

where $\rho_{i} \in(0,1), q_{i} \leq 0$, and $\mu_{i} \geq 0$ for $i=K, L$. Tax news, as modeled by $\varepsilon_{i, t-j}$ for $j=1, \ldots, 4$, is assumed to have an $\mathrm{MA}(4)$ process. For each $i, \varepsilon_{i, t}$ is an i.i.d. random variable. 
When (25) determines tax choices, agents face a signal-extraction problem because, even if they observe the $\varepsilon^{\prime}$ 's one or more quarters in advance, they do not have advance knowledge of $\hat{Y}$ or $\hat{s}^{B}$. In addition, at time $t$ a surprise piece of news, $\varepsilon_{i, t}$, arrives.

Modeling information flows as moving average processes captures the idea that from quarter to quarter news about taxes evolves randomly. News might accumulate, with information improving and concentrating agents' probability distributions over future tax rates. Alternatively, news might disappoint, with agents' expectations frustrated by realizations of $\varepsilon$ 's that suddenly reverse earlier expectations. This randomness captures the vagaries of the political process that determine fiscal choices. We restrict $\sum_{i=0}^{4} \phi_{i}=1$ and $\phi_{4} \in[0,1]$. The $\phi$ 's are interpreted as weights attached to news arriving at different periods, reflecting their importance in affecting the tax policy that is ultimately implemented.

5.2. Generalizing Information Flows. Our analytical examples showed that invertibility hinges on assumptions about information flows and on discount factors that are functions of the deep parameters of the model. To examine the robustness of our results, we apply Fernandez-Villaverde, Rubio-Ramirez, Sargent, and Watson's (2007) condition for invertibility of the moving-average representation to the more general calibrated DSGE model. We find that incorporating real frictions into the model does not ease the problem of noninvertibility. ${ }^{17}$ As long as $\phi_{4}=1$ and $\phi_{3}=\phi_{2}=\phi_{1}=\phi_{0}=0$, so that agents have four quarters of tax foresight, the equilibrium is always noninvertible. However, when news arrives gradually — so that all the $\phi$ 's can be nonzero - there are certain parameter combinations that produce an invertible equilibrium. The crucial factor that determines the impact of foresight on invertibility, therefore, is the process of information flows in the economy.

The model of section 3 with two periods of foresight provides useful intuition. We focus on two aspects of the tax process: the persistence of tax shocks and the process governing the arrival of tax news.

5.2.1. Persistence of Tax Policy. Suppose that the tax process follows $\hat{\tau}_{t}=\rho \hat{\tau}_{t-1}+\varepsilon_{\tau, t-2}$. Optimal capital accumulation is given by

$$
(1-\alpha L)(1-\rho L) k_{t}=\varepsilon_{A, t}-\left(\frac{\tau(1-\theta)}{(1-\tau)(1-\rho \theta)}\right)\left\{(1-\rho \theta) \varepsilon_{\tau, t-1}+\theta \varepsilon_{\tau, t}\right\}
$$

Assuming the econometrician can correctly identify the technology shock, this representation is not invertible if $\theta<(1+\rho)^{-1}$. If the agent discounts recent news more than older news, then the representation continues to be noninvertible. A highly persistent tax rate implies the agent will more smoothly discount the shocks and older news will receive more of a discount vis-á-vis the i.i.d. case in expression (8). If the discount factor is large enough and there is enough persistence in the tax process, the agent will discount in the usual way, yielding an invertible representation so that the optimal capital sequence will reveal the agents' information set.

In the analytical example, however, given $\theta=\alpha \beta(1-\tau)$ and two periods of foresight, any feasible choice of parameters implies (26) will be not be invertible. Moreover, this result continues to hold when the tax rate follows an autoregressive process of length $n$, where $n$ is

\footnotetext{
${ }^{17}$ We perform 10,000 draws from distributions of parameters that yield a unique equilibrium.
} 
greater than or equal to the degree of foresight and is finite. If the tax rate follows an $\operatorname{AR}(n)$ process with two periods of foresight, tedious algebra shows that the root of the moving average component of capital is given by

$$
\theta+z\left(1-\rho_{1} \theta\right)+z^{2} \rho_{3} \theta^{3}+z^{3} \rho_{4} \theta^{4}+\cdots z^{n-1} \rho_{n} \theta^{n}=0 .
$$

The following theorem will be used to show that if $\theta<\left(1+\rho_{1}\right)^{-1}$, then the capital process will not be invertible in the $\operatorname{AR}(n)$ case.

Theorem 1 (Rouché). Suppose that two functions $f$ and $g$ are analytic inside and on a simple closed contour $C$. If $|f(z)|>|g(z)|$ at each point on $C$, then the functions $f(z)$ and $f(z)+g(z)$ have the same numbers of zeros, counting multiplicities, inside $C .{ }^{18}$

Define $f(z) \equiv \theta+z\left(1-\rho_{1} \theta\right)$ and $g(z) \equiv z^{2} \rho_{3} \theta^{3}+z^{3} \rho_{4} \theta^{4}+\cdots z^{n-1} \rho_{n} \theta^{n}$ and note that $f(\cdot)$ has a zero inside the unit circle if $\theta<\left(1+\rho_{1}\right)^{-1}$. Assuming the AR representation is stationary, $\sum_{j=1}^{n} \rho_{j}<1$, gives $f(\cdot)>g(\cdot)$ on the unit circle. Therefore, $f(z)+g(z)$ has a zero inside the unit circle and the representation is not invertible.

5.2.2. News Arrival Process. We now illustrate in the simple analytical model how treating information as flowing according to a moving average process alters the conditions for invertibility. Consider the following tax process, which simplifies (25)

$$
\hat{\tau}_{t}=\phi \varepsilon_{\tau, t-2}+(1-\phi) \varepsilon_{\tau, t-1}
$$

When $\phi \in(0,1)$, there is no exact degree of foresight. $\tau_{t+1}$ depends on information received both last period and two periods ago. The limiting cases, $\phi=\{0,1\}$, imply a capital sequence given by expression (7) (which is invertible) or by expression (8) (which is not invertible), respectively. The parameter $\phi$ dictates the relative importance of the news received by the agents at time $t$ and earlier. The larger is $\phi$, the more weight is given to news received two periods ago when forecasting future tax rates. To see this more clearly, note that the equilibrium capital dynamics are given by

$$
k_{t}=\alpha k_{t-1}+\varepsilon_{A, t}-\left(\frac{(1-\theta) \tau}{1-\tau}\right)\left\{[1-\phi(1-\theta)] \varepsilon_{\tau, t}+\phi \varepsilon_{\tau, t-1}\right\}
$$

If $\phi \approx 1$, the tax process implies agents will down weight more recent news $\left(\varepsilon_{\tau, t}\right)$ relative to older news $\left(\varepsilon_{\tau, t-1}\right)$. This leads to the perverse discounting of news that makes the representation noninvertible. More generally, if more recent news receives the heavier discount, $1-\phi(1-\theta)<\phi$, then the equilibrium will not be invertible, and the information set of the agent will not coincide with the econometrician's.

Major tax news that lays out the future direction of policy tends to arrive several quarters before tax policy changes are implemented. Once tax legislation is proposed, the subsequent negotiations between the two parties in Congress can, but often does not, introduce important changes in the details of a tax proposal. This suggests that in data, the weight on the older news tends to be larger than the weight on more recent news. As a result, the equilibrium is quite likely not to be invertible.

\footnotetext{
${ }^{18}$ See Tutschke and Vasudeva (2005).
} 
5.2.3. Information Flows and Forecast Errors. The extent to which private agents condition on information that cannot be captured by current and past variables that are observable to the econometrician determines the forecast error of an econometric model. The $\phi$ 's in equation (25) indicate the weight given to each piece of tax news, $\varepsilon_{\tau}$, received in previous periods. If $\phi_{4}=1$, then only the innovations dated $t=4$ and earlier will influence the current tax rate.

The analytics in section 3 can be used to show that the information discrepancy depends upon the discount factor $\theta$. Recall that with two quarters of foresight equilibrium capital evolves as

$$
k_{t}=-\frac{\kappa(L+\theta)}{1-\alpha L} \varepsilon_{\tau, t}
$$

The variance of the one-step-ahead forecast error for the agent is given by ${ }^{19}$

$$
\begin{aligned}
E\left[\left(k_{t+1}-E\left[k_{t+1} \mid \varepsilon_{\tau, t}, \varepsilon_{\tau, t-1}, \ldots\right]\right)^{2}\right] & =E\left[\left(\frac{-\kappa(L+\theta)}{1-\alpha L} \varepsilon_{\tau, t+1}-L^{-1}\left[-\frac{\kappa(L+\theta)}{1-\alpha L}+\kappa \theta\right] \varepsilon_{\tau, t}\right)^{2}\right] \\
& =(\kappa \theta)^{2} \sigma_{\tau}^{2}
\end{aligned}
$$

For the econometrician's information set, the variance of the forecast error is given by ${ }^{20}$

$$
\begin{aligned}
E\left[\left(k_{t+1}-E\left[k_{t+1} \mid k_{t}, k_{t-1}, \ldots\right]\right)^{2}\right] & =E\left[\left(\frac{-\kappa(L+\theta)}{1-\alpha L} \varepsilon_{\tau, t+1}-L^{-1}\left[-\frac{\kappa(1+\theta L)}{1-\alpha L}+\kappa\right]\left[\frac{L+\theta}{1+\theta L}\right] \varepsilon_{\tau, t}\right)^{2}\right] \\
& =\kappa^{2} \sigma_{\tau}^{2}
\end{aligned}
$$

The difference between (29) and (30) is the discount factor $\theta$. As $\theta$ approaches unity (zero), the difference between the agent and econometrician's information sets is small (large). If $\theta$ is greater than or equal to 1 , the representation for capital becomes fundamental and the variances of the forecast errors (29) and (30) would coincide.

This reasoning extends to the more complex calibrated model. A necessary condition for a representation, $X_{t}=F(L) \epsilon_{t}$, to be fundamental - and for the variance of the agent's and the econometrician's forecast errors to coincide - is for the determinant of $F(L)$ to have no zeros inside the unit circle. The number and size of the zeros inside the unit circle will determine the size of the econometrician's error when estimating a structural VAR. Smaller numbers indicate a larger discrepancy between the agent's and the econometrician's information sets.

Table 1 is based on the calibrated DSGE model using a tax rule that simplifies (25), $\hat{\tau}_{t}=\phi_{0} \varepsilon_{\tau, t}+\phi_{1} \varepsilon_{\tau, t-1}+\phi_{2} \varepsilon_{\tau, t-2}$. The table reports the multiplication of the zeros of the structural VAR for the calibrated parameters as the informational assumptions of the tax processes varies. We assume $\phi_{3}=\phi_{4}=0$ and $\phi_{1}, \phi_{2} \in(0,1)$ with $\phi_{1}+\phi_{2} \leq 1$ and $\phi_{0}=1-\left(\phi_{1}+\phi_{2}\right)$.

Two points are noteworthy. First, as the minor diagonal indicates, if the tax process does not depend upon contemporaneous innovations (i.e., $\phi_{1}+\phi_{2}=1$ ), the econometrician's estimates will deviate substantially from the truth, with multiplied zeros essentially equal to zero. In these cases the agent observes the tax innovation in advance, making her one-stepahead forecast errors nearly zero. The econometrician does not see the news in advance,

\footnotetext{
${ }^{19}$ These derivations assume the econometrician observes the technology shock exactly.

${ }^{20}$ Note that the variance of the Blaschke factor is unity.
} 


\begin{tabular}{|c|c|c|c|c|c|c|c|c|c|c|}
\hline & & 0.1 & 0.2 & 0.3 & $\begin{array}{r}\phi_{1} \\
\mathbf{0 . 4}\end{array}$ & 0.5 & 0.6 & 0.7 & 0.8 & 0.9 \\
\hline & 0.1 & \multicolumn{5}{|c|}{$\leftarrow 1 \rightarrow$} & .30 & .09 & .02 & $5.3^{*}$ \\
\hline & 0.2 & \multicolumn{4}{|c|}{$\leftarrow 1 \rightarrow$} & .99 & .15 & .02 & $3.8^{*}$ & \\
\hline & 0.3 & \multicolumn{3}{|c|}{$\leftarrow 1 \rightarrow$} & .99 & .44 & .03 & $3.1^{*}$ & & \\
\hline$\phi_{2}$ & 0.4 & 1 & .99 & .56 & .25 & .06 & $2.4^{*}$ & & & \\
\hline & 0.5 & .64 & .36 & .16 & .04 & $2.8^{*}$ & & & & \\
\hline & 0.6 & .25 & .11 & .03 & $1.5^{*}$ & & & & & \\
\hline & 0.7 & .08 & .02 & $1.1^{*}$ & & & & & & \\
\hline & 0.8 & .02 & $0.9^{*}$ & & & & & & & \\
\hline & 0.9 & $.85^{*}$ & & & & & & & & \\
\hline
\end{tabular}

TABLE 1. The entries are the multiplication of the zeros inside the unit circle for the structural VAR representation. Smaller numbers indicate a larger discrepancy between the information set of the agent and econometrician, and unity signifies no discrepancy. A * indicates number multiplied by $10^{-12}$.

making his forecast errors relatively large. Second, table 1 shows the extent to which information flows will alter the errors made by the structural VAR. If most of the weight is on $\phi_{0}$ (upper left part of the table), the structural VAR will not be misspecified. As more weight is placed on $\phi_{1}$ and $\phi_{2}$, the errors become very large.

Evidently, the errors in inference made by the econometrician are very sensitive to information flows. This confirms our belief that accurately specifying information flows is crucial to understanding the effects of fiscal policy. In practice, the legislative and implementation lags associated with fiscal policy create information flows that are likely to produce zeros in $F(L)$ close to the minor diagonal, suggesting large econometric errors. We turn now to a closer examination of the errors.

5.2.4. Robustness to Information Flows. We generalize the information flows underlying table 1 by returning to the specification of tax policy behavior in (25) but randomly drawing the moving-average coefficients - the $\phi$ 's. We fix the model parameters at their calibrated values in table 2 [appendix A] and draw the information parameters, the $\phi$ 's, according to the following distributions:

$$
\phi_{4} \sim 1-\beta(1.5,5) ; \quad \phi_{1}, \phi_{2}, \phi_{3} \sim U[0,0.1]
$$

where the distribution of $\phi_{4}$ is left skewed between 0 and 1 and has a theoretical mean of 0.77 and standard deviation of 0.15 . This distribution assumes that most of the news regarding changes in fiscal policy will be known up to a year in advance. It does not imply, $a$ priori, that the equilibrium process will be nonfundamental. We believe it is a conservative approximation to the actual data generating process for U.S. tax policy in that it understates the degree of foresight in practice. $^{21}$

\footnotetext{
${ }^{21}$ Yang (2008) estimates that the sum of the legislative and implementation lags averages about seven quarters in the United States, while Mertens and Ravn (2008), drawing on the narrative work by Romer and Romer (2007b), figure the median total lag to be six quarters.
} 

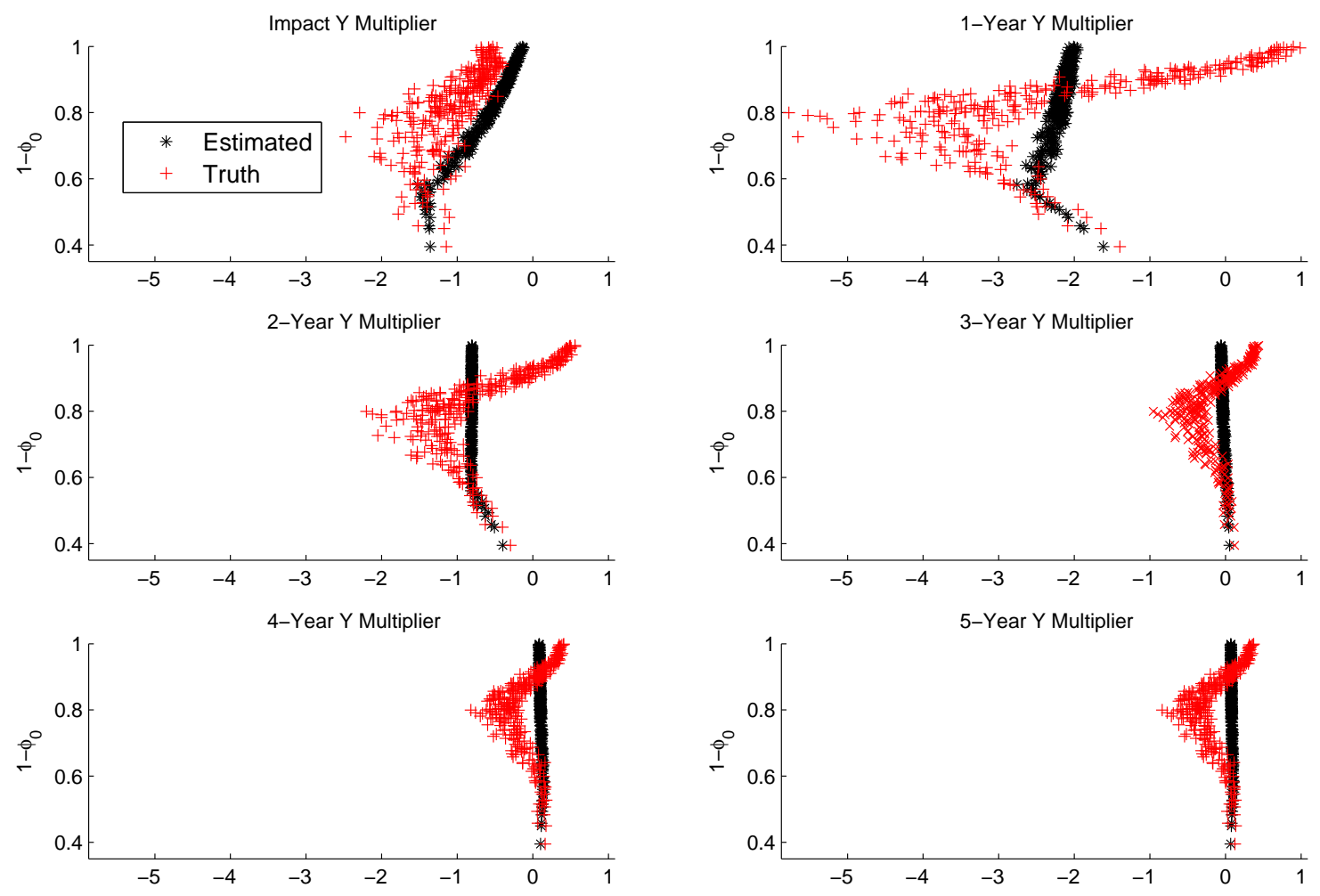

Figure 4. Output Multipliers: True Value $(*)$ and Econometrician's Estimate $(+)$. Anticipated increase in capital taxes using information flows implied by policy rule (25).

For each draw of information parameters $(\phi ' s)$, we simulate 10 datasets of 500 quarters by drawing from the seven structural shocks. We estimate the VAR with the following variables: capital tax rate, revenues, non-durable consumption, durable consumption, investment, output, and government debt. ${ }^{22}$ The tax effects reported by the econometrician for each draw of information parameters are the mean responses estimated from the 10 simulated datasets. To separate the issue of identification from invertibility, we assume that the econometrician has the exact income elasticity, $\mu_{i}$ for $i=K, L$, in identifying the structural tax shocks. We confirm that if no foresight is present, this identification strategy delivers accurate estimates. ${ }^{23}$

Figures 4-6 plot the actual (denoted $*$ ) and the estimated (denoted + ) tax multipliers at various horizons. The multipliers are dollar changes in output, nondurable consumption, and investment due to an anticipated increase in the capital tax rate. Impulse responses are normalized so that the peak response in revenues equals $\$ 1$. Multipliers are plotted against $1-\phi_{0}$ on the vertical axes, which serves as a measure of the degree of foresight: when $\phi_{0}=0$

\footnotetext{
${ }^{22}$ Results are invariant to alternative conditioning variables.

${ }^{23}$ This assumption is not innocuous. Foresight may make it extremely difficult to reliably estimate the $\mu_{i}$ elasticities. We abstract from this difficulty, so our results are the best case scenario for the econometrician.
} 

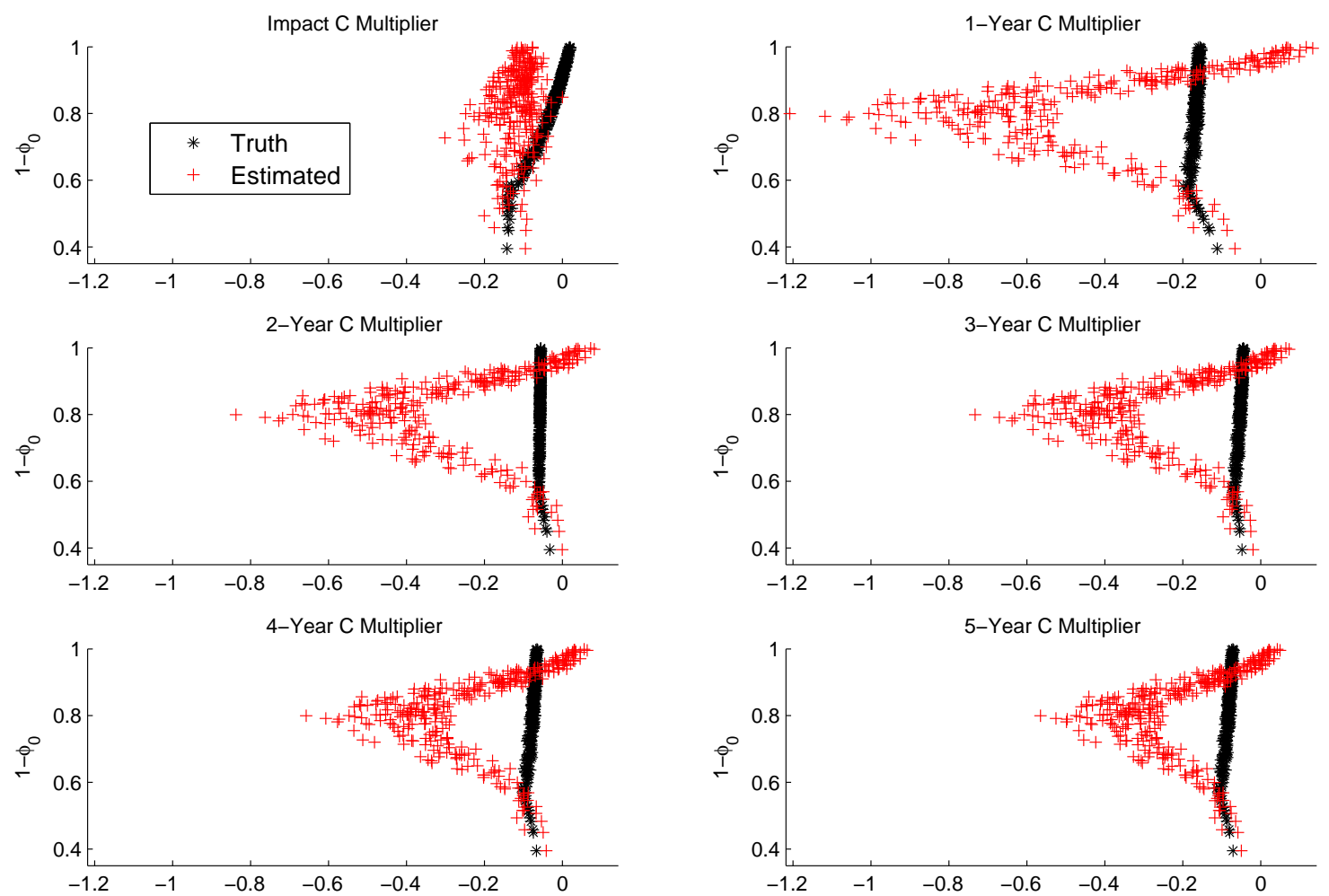

Figure 5. Nondurable Consumption Multipliers: True Value $(*)$ and Econometrician's Estimate $(+)$. Anticipated increase in capital taxes using information flows implied by policy rule (25).

there is no exogenous surprise in tax rates; when $\phi_{0}=1$ there is no exogenous advanced news about tax rates.

Empirical estimates of output multipliers following a $\$ 1$ surprise change in tax revenues vary widely. Blanchard and Perotti (2002) estimate a peak response of output between -\$1.33 and $-\$ 0.78$, while Mountford and Uhlig (2008) estimate a much larger response of -\$3.23. The multipliers in figures $4-6$ are not strictly comparable because they pertain to an anticipated increase in the capital tax rate that raises revenues by $\$ 1$, with no correlated shock to the labor tax rate.

The figures show that as the degree of foresight varies - along the vertical axis - the econometrician's estimated multipliers can deviate dramatically from the truth. The bias is largest at the one-year horizon, which coincides with the maximum degree of foresight. Biases can be very large: $\$ 3$ for output, a factor of five for consumption, and a factor of two or more for investment.

Biases tend to be smaller at longer horizons for both output and investment. This tendency does not carry over to consumption, where the bias continues to be substantial even five years after the tax news arrives. This difference is explained in the next section. 

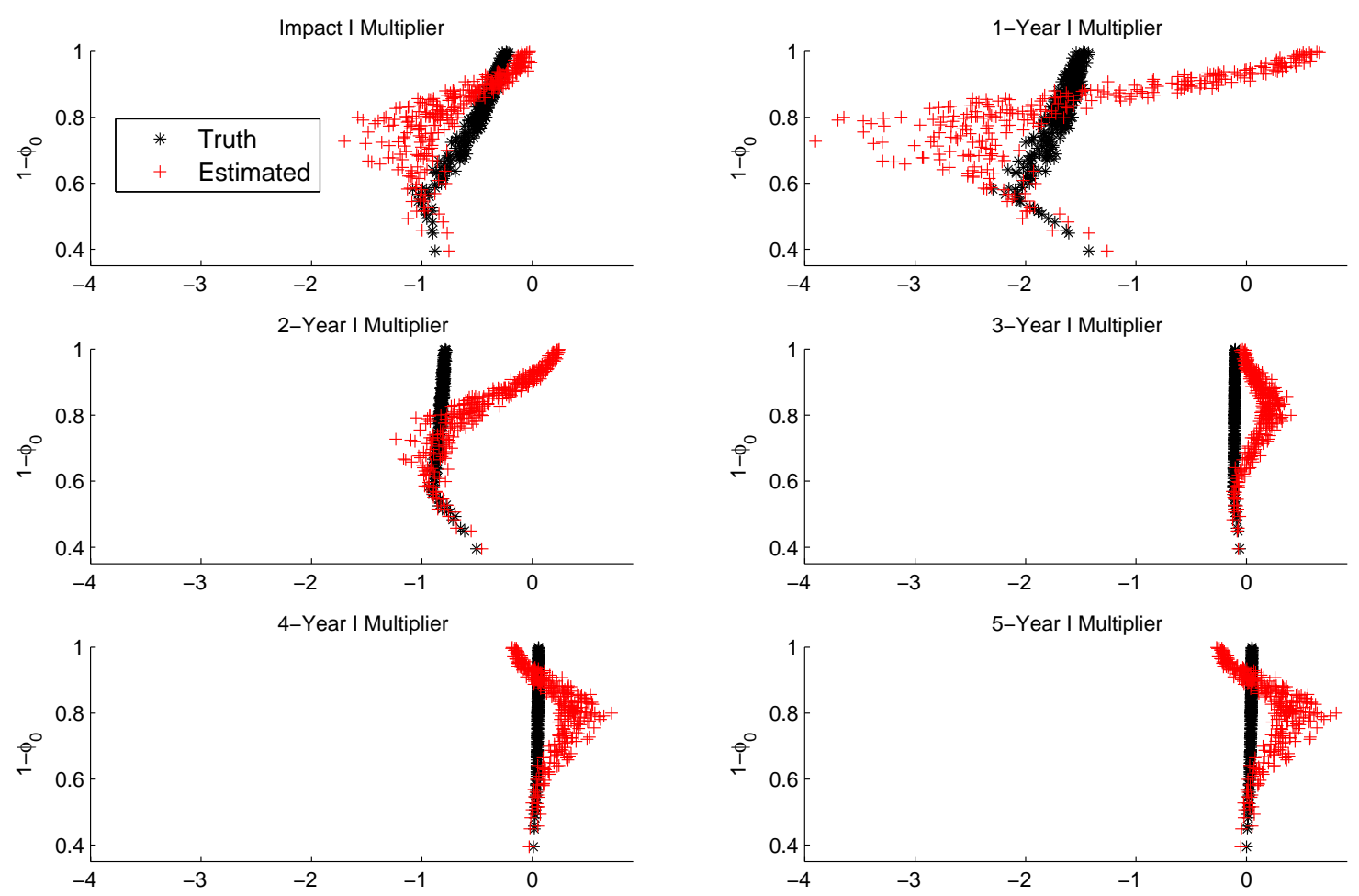

Figure 6. Investment Multipliers: True Value $(*)$ and Econometrician's Estimate $(+)$. Anticipated increase in capital taxes using information flows implied by policy rule (25).

The figures also make clear that biases can be of any sign. Even when news of a future rise in capital tax rates actually reduces output in the short run, there are information flows that rationalize a diverse set of econometric inferences: the one-year estimated multiplier could range from $\$ 1$ to $-\$ 5$. Figures $2 \mathrm{a}$ and $3 \mathrm{a}$ show that the simple analytical model can produce the range of inferences of anticipated tax effects that appears in empirical work. Figures 4-6 make the analogous point in a calibrated DSGE model drawn from the class of models in use for policy analysis.

5.2.5. Robustness to Internal Propagation. It is important to understand how aspects of the model (e.g., parameters or assumptions) alter the effects of foresight. The internal propagation mechanisms built into many macroeconomic models are introduced to better match important empirical characteristics. For example, investment adjustment costs are introduced to elongate impulse response functions so that investment shocks have a smoother, more persistent effect on economic activity. Figure 7 demonstrates the response of investment to a tax shock as the investment adjustment cost parameter changes from 0.5 to 0 . The dotted-dashed lines are the true responses of investment to news of a higher capital tax 


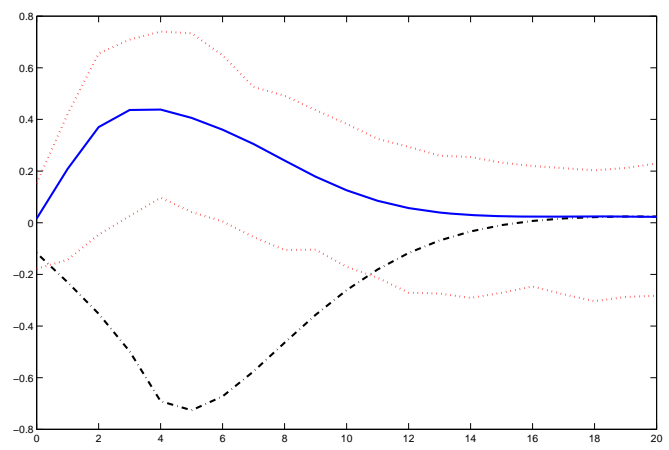

Figure 7a: With Adjustment Costs $(\gamma=0.5)$

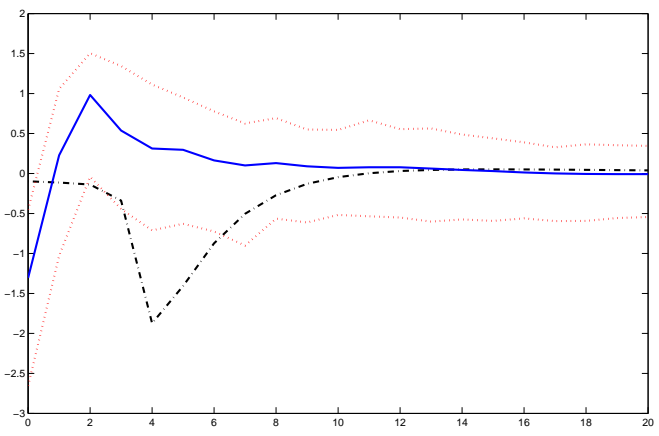

Figure 7b: Without Adjustment Costs $(\gamma=0)$

Figure 7. Response of Investment to Higher Anticipated Capital Tax Rate. True responses (dotted-dashed lines) and means (solid lines) and 95\% error bands (dotted lines) of estimated responses.

rate, while the solid lines are the means of the econometrician's estimated responses and the dotted lines are $95 \%$ error bands. ${ }^{24}$

With investment adjustment costs turned off (figure $7 \mathrm{~b}$ ), the reaction at the quarter of foresight, period four, is abrupt while the periods leading up to the quarter of foresight are relatively unresponsive. With high adjustment costs (0.5), the model penalizes rapid adjustments to investment and the agent slowly reduces investment in the periods before the quarter of foresight. As the figure demonstrates, introducing frictions into the model implies that the econometrician will not only misspecify short-run dynamics but potentially medium-term dynamics as well.

5.2.6. Effects of Other Shocks. Interestingly, we do not find much evidence of misspecification of non-foresight shocks in the model. The analytical results of section 4 suggest that the econometrician will not only draw incorrect inferences regarding the fiscal shocks but all remaining shocks of the estimated VAR will also be misspecified. To examine this, we identify the government spending shock and assume agents have no foresight with respect to this shock. The true impulse response functions were all very close to the structural VAR estimates; the lone exception is investment, which falls outside of the $90 \%$ error band.

While this suggests that foresight might not impinge on the identification of other shocks, we offer two important caveats. First, in our simulation exercises, we give the econometrician the exact parameters of the model necessary for identifying the shocks. This is done to pinpoint the effects of foresight. If instead we were to assume that the econometrician must estimate these parameters, the results would look much worse. Second, and perhaps more importantly, many recent papers argue that foresight should be extended in many directions [e.g., Schmitt-Grohe and Uribe (2008)]. Indeed, Ramey (2007) argues forcefully that agents will have knowledge of a government spending shock long before it hits the economy. There

\footnotetext{
${ }^{24}$ Based on 100 simulated data sets of length 245 quarters.
} 
is no doubt that the introduction of multiple sources of foresight and, therefore of possible noninvertibility, will dramatically magnify the size of the error for all shocks.

\section{Concluding Remarks: Attacking the Problem}

We have explicitly shown how fiscal foresight introduces econometric difficulties that complicate the interpretation of conventional econometric analyses. The crux of the issue is that foresight, of any type, can introduce nonfundamental moving average representations into the linear equilibrium process. This implies that the mapping between the true tax news that agents observe and the "tax shocks" that the econometrician identifies can be vastly different. Many of the econometric techniques in macroeconomists' toolboxes -impulse response functions, variance decompositions, Granger-causality tests, tests of cross-equation restrictions - can be distorted by empirical methods that do not adequately estimate the non-invertible moving average components of equilibrium time series. Section 5 demonstrates that foresight is quantitatively important in the class of models now in wide use for macro policy analysis.

Using theory to understand the econometric problems associated with fiscal foresight is a necessary first step toward developing econometric techniques to correct for potential noninvertibility problems. The macroeconomic literature does not take a theoretical approach to identify the effects of fiscal foresight; that empirical work has also produced a wide range of results. This paper explains the wide range of inferences as stemming from confronting the econometric work with alternative assumptions about the flow of information about tax changes.

Two lines of attack appear in the empirical macro literature. The first estimates conventional VARs, identified in a variety of creative ways to isolate "anticipated taxes," and then examines the impacts of fiscal foresight ex-post [Sims (1988), Blanchard and Perotti (2002), Yang (2007), Mountford and Uhlig (2008)]. A second line rejects VAR identification schemes ex-ante, arguing that they cannot adequately measure the impacts of foreseen changes in fiscal policy, and takes a different-narrative - approach to identification that brings fresh data to bear on the problem [Ramey and Shapiro (1998), Edelberg, Eichenbaum, and Fisher (1999), Ramey (2007), Romer and Romer (2007a), Mertens and Ravn (2008)]. Unfortunately, as noted earlier, no consensus about the impacts of anticipated tax changes has emerged from either line of attack.

The explicit analytical characterization of fiscal foresight that we present allows one to understand these diverse approaches within a single framework: both the ex-post and exante approaches share the aim of finding instrumental variables for news about future tax changes. Returning to the simple model of section 3 , the equilibrium representation of capital is invertible in current and future capital, implying that a good instrument for the tax news that arrives at $t$ would be highly correlated with a particular weighted average of current and future capital: ${ }^{25}$

$$
k_{t}=\left(\alpha^{-1}+\theta\right) k_{t+1}-\theta\left(\alpha^{-1}+\theta\right) k_{t+2}+\theta^{2}\left(\alpha^{-1}+\theta\right) k_{t+3}-\cdots+\alpha^{-1} \kappa \varepsilon_{\tau, t} .
$$

\footnotetext{
${ }^{25}$ Although the simple mapping (32) emerges from this stylized example, any given theoretical model will yield an analogous mapping that produces an object with which a good instrument should be correlated.
} 
In Leeper, Walker, and Yang (2008) we analyze the efficacy of the ex-ante and ex-post approaches. We provide conditions under which each approach delivers as a valid instrument. We argue that the diverse results can largely be attributed to the quality of the instrumental variable. Performance quality depends entirely on auxiliary assumptions about, for example, information flows and tax policy behavior. Both the ex-ante and ex-post approaches help to alleviate the informational discrepancy between the agent and the econometrician, but they do not obviate the need to confront the difficult issues associated with modeling information flows and identifying exogenous fiscal actions. As our results in the previous section highlight, slight deviations in information flows can dramatically alter conclusions about fiscal policy behavior.

A third, less macro-oriented, empirical approach is associated with Poterba (1989), Fortune (1996), and Park (1997). Those papers exploit the differential tax treatment of municipal bonds and other bonds, such as treasury and corporate securities, to identify innovations in yield spreads with news about tax policy changes. When markets are efficient, asset prices reflect all information currently available to market participants, especially news concerning the future paths of relevant variables. Because asset prices react quickly to news, conditioning on asset prices should alleviate the discrepancy between the agents' and the econometrician's information sets. This hypothesis led Beaudry and Portier (2006) to include stock prices in a VAR in order to capture agents' expectations about future changes in productivity. Asset price movements are notoriously difficult to interpret. It is hard to disentangle the movement in asset prices associated with news from other sources of variation (e.g., changes in risk premia). ${ }^{26}$ Ideally, the asset could be decomposed along some measurable dimension to identify changes in news. Consider the case of fiscal foresight and municipal bonds. If $R_{m}$ is the yield on a municipal bond and $R$ the yield on a taxable bond, then an "implicit tax rate" can be calculated as $\tau=1-R_{m} / R$, assuming the bonds have the same term to maturity and credit risk. This is the tax rate at which the investor is indifferent between the tax-exempt and taxable bonds. If participants in the municipal bond market are forward looking, the implicit tax rate should predict subsequent movements in individual tax rates. Several papers document the ability of the municipal bond market to forecast changes in fiscal policy [Poterba (1989), Fortune (1996), Park (1997)].

Finally, it is straightforward to use standard methods, such as An and Schorfheide (2007), to estimate a model with foresight. This is the approach taken in Schmitt-Grohe and Uribe (2008), who make very particular assumptions about the information flows that give rise to foresight about technology and government spending. The tradeoff is that the modeler must be explicit about the role of information in the economy. As table 1 and figures 4-6 document, different assumptions about information flows can dramatically alter the dynamics of the model and the associated econometric inferences. Robust results may emerge from making the distribution of information more flexible. A tricky aspect of this endeavor is that misspecification of information flows is likely to get confounded with other types of misspecification, which is why it is essential to check for robustness of findings across specifications of information flows.

\footnotetext{
${ }^{26}$ This identification is less problematic for tax foresight than it is in Beaudry and Portier's (2006) environment. News about technology amounts to a latent variable that provides information about an unobservable; news about taxes, on the other hand, is a latent variable informing about a measurable object - tax rates or revenues.
} 
This paper is the first to document theoretically the important empirical implications generated by foresight. Future research will focus on developing the theoretical and econometric techniques necessary to handle the issues implied by the analytical framework examined here. Progress in identifying the dynamic impacts of tax changes calls for a fresh perspective on the problem that carefully models the information flows that underlie fiscal foresight. 


\section{Appendix A. A Model with Real Rigidities}

A.1. The Model Economy. The economy includes several features commonly added to real business cycle (RBC) models to improve their fit to data. Basic RBC models, while capable of producing comparable moments of many key macroeconomic variables [Prescott (1986) and King and Rebelo (1999)], rely heavily on technology shocks to generate fluctuations in aggregate economic activity. The literature, however, cannot identify a large single shock that is as quantitatively important as implied by the model [Cochrane (1994)]. Features such as variable factor utilization rates and durable goods consumption are designed to enhance the propagation mechanisms of the RBC model [Bils and Cho (1994) and ?]. In addition, models without frictions adjustment too quickly to innovations, inconsistent with empirical findings. Features such as habit formation, deliberation costs, and investment adjustment costs are intended to capture the sluggish responses found in estimates VARs [Burnside, Eichenbaum, and Fisher (2004)].

A.1.1. Preferences. A representative household derives utility from three sources: nondurable goods consumption $\left(C_{t}\right)$, durable goods consumption $\left(D_{t}\right)$, and leisure $\left(1-L_{t}\right)$. It incurs disutility from working and making decisions on durable good purchases. The utility function takes the form

$$
U_{t} \equiv \frac{\left[\left(C_{t}^{*}\right)^{1-\frac{1}{\sigma}}+v D_{t}^{1-\frac{1}{\sigma}}\right]^{\frac{1-\frac{1}{\tau}}{1-\frac{1}{\sigma}}}}{1-\frac{1}{\tau}}-\frac{\varphi}{2} \frac{\left(D_{t}-D_{t-1}\right)^{2}}{D_{t-1}}+\chi_{t} \frac{\left(1-L_{t}\right)^{1-\theta}-1}{1-\theta} .
$$

Consumption enters the utility function in the form of $C_{t}^{*} \equiv C_{t}-b C_{t-1}$, where $b \geq 0$, indicating the degree of habit formation. $\tau$ and $\sigma$ are the elasticities of intertemporal and intratemporal substitution in consumption. $\theta$ is the inverse of the elasticity of intertemporal substitution in leisure. $\chi_{t}$ is the preference weight on leisure, subject to i.i.d. shocks $\varepsilon_{t}^{\chi}$; $\chi_{t}=\chi e^{\varepsilon_{t}^{\chi}}$ and $\varepsilon_{t}^{\chi} \sim N\left(0, \sigma_{\chi}^{2}\right)$. The quadratic term $-\frac{\varphi}{2} \frac{\left(D_{t}-D_{t-1}\right)^{2}}{D_{t-1}}(\varphi>0)$ captures disutility from changing the durable stock, often interpreted as deliberation costs.

The infinitely lived household maximizes expected lifetime utility

$$
E_{0} \sum_{t=0}^{\infty} \beta^{t} \xi_{t} U_{t}
$$

subject to the budget constraint

$$
C_{t}+D_{t}+I_{t}+B_{t}=\left(1-\tau_{t}^{L}\right) W_{t} L_{t}+\left(1-\tau_{t}^{K}\right) r_{t} u_{t} K_{t-1}+\left(1-\delta_{D}\right) D_{t-1}+R_{t-1} B_{t-1}+T_{t},
$$

and the law of motion for capital

$$
K_{t}=\left(1-\delta_{t}\right) K_{t-1}-\Omega\left(I_{t}, I_{t-1}\right) .
$$

$\xi_{t}$ is an i.i.d. shock to the rate of discount, with $\xi_{t}=\xi e^{\varepsilon_{t}^{\xi}} . B_{t}$ is government debt issued at time $t$, which pays $R_{t} B_{t}$ units of goods at $t+1$. $I_{t}$ is gross investment, including investment adjustment costs. As in Burnside, Eichenbaum, and Fisher (2004), we assume the net investment takes the form $\Omega(\cdot) \equiv\left[1-\Gamma\left(\frac{I_{t}}{I_{t-1}}\right)\right] \times I_{t}$, where $\Gamma(1)=\Gamma^{\prime}(1)=0$ and $\Gamma^{\prime \prime}(1) \equiv$ $\gamma>0 .{ }^{27} \tau_{t}^{L}$ and $\tau_{t}^{K}$ are marginal labor and capital income tax rates, and $T_{t}$ is lump-sum

\footnotetext{
${ }^{27}$ The method of solution does not require the specification of $\Gamma(\cdot)$, only $\gamma$.
} 
transfers. $W_{t}$ is the wage rate for labor. Finally, $u_{t}$ is the capital utilization rate and $r_{t}$ is the rental rate for one effective unit of capital, $u_{t} K_{t-1}$.

We assume a constant depreciation rate for durables, $\delta_{D}$, but not for capital. As in ?, using capital more intensively makes capital depreciate at a faster rate. The depreciation rate of capital has the form

$$
\delta_{t}=\delta u_{t}^{\omega}
$$

where $0<\delta<1$ and $\omega>1$.

A.1.2. Production. A representative firm rents capital and labor from households to maximize profit

$$
Y_{t}-W_{t} L_{t}-r_{t} u_{t} K_{t-1} .
$$

It produces goods according to the technology

$$
Y_{t}=A_{t}\left(u_{t} K_{t-1}\right)^{\alpha} L_{t}^{1-\alpha}
$$

Technology, $A_{t}$, evolves according to

$$
\ln A_{t}=\rho_{A} \ln A_{t-1}+\varepsilon_{t}^{A} .
$$

A.1.3. Government. Government each period sells one-period bonds and collect tax revenues to pay for its expenditures on government consumption $\left(G_{t}\right)$ and transfers and to service its debt obligations $R_{t-1} B_{t-1}$. The government's budget constraint at each date is

$$
B_{t}=G_{t}+R_{t-1} B_{t-1}-\tau_{t}^{L} W_{t} L_{t}-\tau_{t}^{K} r_{t} u_{t} K_{t-1}+T_{t}
$$

To maintain budget solvency, fiscal variables adjust in response to changes of government indebtedness, as measured by deviations of the debt-output ratio $\left(s_{t}^{B} \equiv \frac{B_{t}}{Y_{t}}\right)$ from its steady state level. Fiscal rules in log-linearized form (variables denoted by ${ }^{\wedge}$ ) are as follows.

Transfer-output ratio, $s_{t}^{T} \equiv \frac{T_{t}}{Y_{t}}$

$$
\hat{s}_{t}^{T}=\rho_{T} \hat{s}_{t-1}^{T}+q_{T} \hat{s}_{t-1}^{B}+\varepsilon_{t}^{T},
$$

where $0<\rho_{T}<1, q_{T} \leq 0, \varepsilon_{t}^{T}$ is an i.i.d. transfer shock, and $\varepsilon_{t}^{T} \sim N\left(0, \sigma_{T}^{2}\right)$

Government spending-output ratio, $s_{t}^{G} \equiv \frac{G_{t}}{Y_{t}}$

$$
\hat{s}_{t}^{G}=\rho_{G} \hat{s}_{t-1}^{G}+q_{G} \hat{s}_{t-1}^{B}+\varepsilon_{t}^{G},
$$

where $0<\rho_{G}<1, q_{G} \leq 0, \varepsilon_{t}^{G}$ is an i.i.d. government spending shock, and $\varepsilon_{t}^{G} \sim N\left(0, \sigma_{G}^{2}\right)$

Labor and capital tax rates are specified in (25).

A.2. Benchmark Calibration. The model is calibrated at a quarterly frequency. Table 2 summarizes the benchmark calibration. The benchmark calibration assumes four quarters of foresight $\left(\phi_{4}=1\right)$ and implies a steady state nondurable consumption-output ratio of 0.60, durable expenditures-output ratio of 0.09 , investment-output ratio of 0.12 , government consumption-output ratio of 0.20 , and debt-output ratio of 0.44 . The corresponding average 


\begin{tabular}{|ll|ll|ll|}
\hline Parameter & Value & Parameter & Value & Parameter & Value \\
\hline$\alpha$ & .36 & $\tau^{L}$ & .2 & $\xi$ & 1 \\
$\beta$ & .99 & $\tau^{K}$ & .39 & $\omega$ & 1.9 \\
$\theta$ & 1 & $s^{T}$ & .064 & $\gamma$ & .3 \\
$\delta$ & .02 & $s^{G}$ & .2 & $\tau$ & .6 \\
$\delta_{D}$ & .025 & $q_{T}$ & -.02 & $\sigma$ & 1.05 \\
$\rho_{T}, \rho_{G}, \rho_{K}, \rho_{L}$ & .9 & $q_{G}$ & -.02 & $\sigma_{G}$ & .015 \\
$\rho_{A}$ & .95 & $q_{K}, q_{L}$ & .01 & $\sigma_{A}$ & .007 \\
$\mu^{K}$ & 1 & $\varphi$ & 4 & $\sigma_{K}, \sigma_{L}$ & .02 \\
$\mu^{L}$ & .2 & $b$ & .5 & $\sigma_{\xi}, \sigma_{\chi}, \sigma_{T}$ & .005 \\
\hline
\end{tabular}

TABLE 2. Benchmark calibration.

\begin{tabular}{|l|cc|cc|cc|}
\hline & \multicolumn{2}{|c|}{ Relative s.d. in \% } & \multicolumn{2}{c|}{ Correl. with output } & \multicolumn{2}{c|}{ 1st-order AR } \\
\hline & Model & Data & Model & Data & Model & Data \\
\hline Output & 1 & 1 & 1 & 1 & .74 & .84 \\
Nondurables & .39 & .47 & .84 & .78 & .81 & .78 \\
Durables & 3.13 & 3.09 & .80 & .58 & .43 & .72 \\
Investment & 5.74 & 4.79 & .83 & .83 & .88 & .78 \\
Labor & .75 & .88 & .36 & .87 & .69 & .91 \\
Govt Spending & 2.51 & 2.14 & .06 & .17 & .74 & .90 \\
Capital Tax Rev. & 3.64 & 3.11 & .41 & .54 & .78 & .83 \\
Labor Tax Rev. & 2.71 & 3.53 & .18 & .78 & .68 & .78 \\
\hline
\end{tabular}

TABLE 3. Business cycle statistics for the model and the U.S. Economy, 1947:1Q-2008:2Q: relative standard deviations are in percent; 1st-order AR is the autoregressive coefficient for each series.

ratios in the U.S. data from 1947:1Q to 2008:2Q are $0.56,0.08,0.16,0.20$, and 0.42 , respectively. $^{28}$ Other statistics, based on 1000 simulations, are summarized in table 3. For each variable of interest, the Hodrick-Prescott filter is applied to simulated data in logarithm. For each series, we compute standard deviations in percent normalized by the standard deviation of output, contemporaneous correlation coefficients with output, and the coefficient of the first-order autoregressive process. The model produces business cycle moments comparable to the postwar U.S. data for most variables examined here. ${ }^{29}$

One caveat is that the model generates much weaker positive correlation between output and labor than the empirical counterpart. Two main factors dampen the correlation between output and labor. First, the automatic stabilizer built in the labor income tax rule raises the labor income tax rate when output rises, which suppresses the positive response of labor to a shock that increases output. Second, in response to a technology shock, the current model

\footnotetext{
${ }^{28}$ The debt-output ratio is based on the average ratio of federal debt held by the public as computed in table B-79 of Economic Report of the President (2008), from 1947 to 2007.

${ }^{29}$ The data counterpart is taken as aggregate hours of wage and salary workers on nonfarm payrolls by sector, available at ftp://ftp.bls.gov/pub/special.requests/opt/tableb10.txt. Data counterpart of government spending is government consumption and investment of all levels of government. Capital and labor income tax revenues are constructed based on Jones's (2002) definitions.
} 
with real rigidities such as habit formation and investment adjustment costs suppress the quick movement in labor and dampens the positive contemporaneous correlation between output and labor. 


\section{REFERENCES}

ABel, A. B. (1982): "Dynamic Effects of Permanent and Temporary Tax Policies in a q Model of Investment," Journal of Monetary Economics, 9(3), 353-373. 8

Adolfson, M., S. Laseen, J. Linde, and M. Villani (2007): "RAMSES-A New General Equilibrium Model for Monetary Policy Analysis," Sveriges Riksbank Economic Review, (2), 5-39. 17

An, S., And F. Schorfheide (2007): "Bayesian Analysis of DSGE Models," Econometric Reviews, 26(2-4), 113-172. 27

Auerbach, A. J. (1989): "Tax Reform and Adjustment Costs: The Impact on Investment and Market Value," International Economic Review, 30(4), 939-962. 8

Auerbach, A. J., And J. Slemrod (1997): "The Economic Effects of the Tax Reform Act of 1986," Journal of Economic Literature, 35(2), 589-632. 1, 4

Beaudry, P., And F. Portier (2006): "Stock Prices, News, and Economic Fluctuations," American Economic Review, 96(4), 1293-1307. 3, 27

Bils, M., AND J.-O. Cho (1994): "Cyclical Factor Utilization," Journal of Monetary Economics, 33(2), 319-354. 29

Blanchard, O. J., and R. Perotti (2002): "An Empirical Characterization of the Dynamic Effects of Changes in Government Spending and Taxes on Output," Quarterly Journal of Economics, 117(4), 1329-1368. 1, 10, 23, 26

Blattner, T., M. Catenaro, M. Ehrmann, R. Strauch, and J. Turunen (2008): "The Predictability of Monetary Policy," European Central Bank Occasional Paper No. 83. 4

Branson, W. H., A. Fraga, and R. A. Johnson (1986): "Expected Fiscal Policy and the Recession of 1982," in Prices, Competition, and Equilibrium, ed. by M. H. Peston, and R. E. Quandt, pp. 109-128. Barnes \& Noble, Totowa, New Jersey. 1, 4

Braun, R. A. (1994): "Tax Disturbances and Real Economic Activity in the Postwar United States," Journal of Monetary Economics, 33(June), 441-462. 1

Burman, L. E., K. A. Clausing, and J. F. O'Hare (1994): “Tax Reform and Realizations of Capital Gains in 1986," National Tax Journal, 47(1), 1-18. 1, 5

Burnside, C., M. Eichenbaum, And J. D. M. Fisher (2004): "Assessing the Effects of Fiscal Shocks," Journal of Economic Theory, 115(1), 89-117. 29

Campbell, J. Y., And R. J. Shiller (1987): "Cointegration and Tests of Present Value Models," Journal of Political Economy, 95(5), 1062-1088. 15, 16

Christiano, L. J., M. Eichenbaum, and C. L. Evans (2005): "Nominal Rigidities and the Dynamic Effects of a Shock to Monetary Policy," Journal of Political Economy, 113(1), 1-45. 17

Christiano, L. J., C. Ilut, R. Motto, and M. Rostagno (2007): "Monetary Policy and Stock Market Boom-Bust Cycles," Manuscript, Northwestern University. 3, 12

Chung, H., And E. M. Leeper (2007): "What Has Financed Government Debt?," NBER Working Paper No. 13425. 2

Cochrane, J. H. (1994): "Shocks," Carneige-Rochester Conference Series on Public Policy, 41, 295-364. 29 
Coenen, G., and R. Straub (2004): "Non-Ricardian Households and Fiscal Policy in an Estimated DSGE Model of the Euro Area," Manuscript, European Central Bank. 1

Congressional Budget Office (2002): "Capital Gains Taxes and Federal Revenues," Revenue and Tax Policy Brief. 4

Cooley, T. F., And M. Dwyer (1995): "Business Cycle Analysis Without Much Theory: A Look at Structural VARs," Journal of Econometrics, 83(1-2), 57-88. 2

Deaton, A. S. (1987): "Life-Cycle Models of Consumption: Is the Evidence Consistent with the Theory?," in Advances in Econometrics: Fifth World Congress, ed. by T. F. Bewley, vol. II, pp. 121-148. Cambridge University Press, New York. 3

Dungey, M., And R. Fry (2007): "The Identification of Fiscal and Monetary Policy in a Structural VAR," CAMA Working Paper 29/2007, Australian National University. 2

Economic Report of the President (2008): United States Government Printing Office. Washington, D.C. 31

Edelberg, W., M. Eichenbaum, and J. D. M. Fisher (1999): "Understanding the Effects of a Shock to Government Purchases," Review of Economic Dynamics, 2(1), 166206. 6,26

Faust, J., J. H. Rogers, E. Swanson, and J. H. Wright (2003): "Identifying the Effects of Monetary Policy Shocks on Exchange Rates Using High Frequency Data," Journal of the European Economic Association, 1(5), 1031-1057. 2

Faust, J., E. Swanson, and J. H. Wright (2004): "Identifying VARs Based on High Frequency Futures Data," Journal of Monetary Economics, 51(6), 1107-1131. 2

Federal Reserve Bank of New York (1986): "Monetary Policy and Open Market Operations in 1985," Federal Reserve Bank of New York Quarterly Review, 11(1), 34-53. 5

(1987): "Monetary Policy and Open Market Operations in 1986," Federal Reserve Bank of New York Quarterly Review, 12(1), 35-56. 5

Feldstein, M., And D. R. Feenberg (1996): "The Effect of Increased Tax Rates on Taxable Income and Economic Efficiency: A Preliminary Analysis of the 1993 Tax Rate Increase," in Tax Policy and the Economy, ed. by J. Poterba, vol. 10, pp. 89-117. MIT Press, Cambridge. 6

Fernandez-Villaverde, J., J. F. Rubio-Ramirez, and T. J. Sargent (2005): “A, B, C's (and D)'s for Understanding VARs," NBER Technical Working Paper 308. 3

Fernandez-Villaverde, J., J. F. Rubio-Ramirez, T. J. Sargent, and M. W. Watson (2007): "ABCs (and Ds) of Understanding VARs," American Economic Review, $97(3), 1021-1026.2,3,18$

Forni, L., L. Monteforte, and L. Sessa (2006): "Keynes vs. Ricardo: Revisiting the Effects of Fiscal Policy in an Estimated DSGE Model for the Euro Area," Manuscript, Bank of Italy. 1

Fortune, P. (1996): "Do Municipal Bond Yields Forecast Tax Policy?," Federal Reserve Bank of Boston New England Economic Review, September/October, 29-48. 27

FRY, R., And A. R. PAgan (2005): "Some Issues in Using VARs for Macroeconometric Research," CAMA Working Paper 19/2005, Australian National University. 2

Giannone, D., And L. Reichlin (2006): "Does Information Help Recovering Structural Shocks from Past Observations?," Journal of the European Economic Association, 4(2-3), 455-465. 2 
Giannone, D., L. Reichlin, and L. Sala (2006): "VARs, Common Factors and the Empirical Validation of Equilibrium Business Cycle Models," Journal of Econometrics, 132(1), 257-279. 2

Goolsbee, A. (2000): "Its Not About the Money: Why Natural Experiments Dont Work on the Rich.," in Does Atlas Shrug: The Economic Consequences of Taxing the Rich, ed. by J. Slemord, pp. 141-158. Harvard University Press, Cambridge, MA. 6

Granger, C. W. J. (1969): "Investigating Causal Relations by Econometric Models and Cross-spectral Methods," Econometrica, 37(3), 424-438. 16

Hansen, L. P., W. Roberds, and T. J. SArgent (1991): "Time Series Implications of Present Value Budget Balance and of Martingale Models of Consumption and Taxes," in Rational Expectations Econometrics, ed. by L. P. Hansen, and T. J. Sargent. Westview Press, Boulder, CO. 15

Hansen, L. P., And T. J. SARgent (1980): "Formulating and Estimating Dynamic Linear Rational Expectations Models," Journal of Economic Dynamics and Control, 2, 7-46. 2

- (1991): "Two Difficulties in Interpreting Vector Autoregressions," in Rational Expectations Econometrics, ed. by L. P. Hansen, and T. J. Sargent, pp. 77-119. Westview Press, Boulder, CO. 2, 9, 14

Holmsen, A., J. F. Qvigstad, and O. Roisland (2007): "Implementing and Communicating Optimal Monetary Policy," Staff Memo No. 2007/3, Norges Bank. 3

House, C. L., And M. D. Shapiro (2006): "Phased-in Tax Cuts and Economic Activity," American Economic Review, 96(5), 1835-1849. 1, 6

- (2008): "Temporary Investment Tax Incentives: Theory with Evidence from Bonus Depreciation," American Economic Review, 98(3), 737-768. 6

Jaimovich, N., and R. Sergio (2008): "Can News About the Future Drive the Business Cycle?," . 3, 8

Johnson, D. S., J. A. Parker, And N. S. Souleles (2004): "Household Expenditure and the Income Tax Rebates of 2001," Manuscript, Princeton University. 7

Jones, J. B. (2002): "Has Fiscal Policy Helped Stabilize the Postwar U.S. Economy?," Journal of Monetary Economics, 49(May), 709-746. 31

JudD, K. L. (1985): "Short-Run Analysis of Fiscal Policy in a Perfect-Foresight Model," Journal of Political Economy, 93(2), 298-319. 8

KAmps, C. (2007): "Dynamic Scoring in an Estimated DSGE Model of the U.S. Economy," Manuscript, European Central Bank. 1

Kapetanios, G., A. R. Pagan, And A. Scott (2005): "Making a Match: Combining Theory and Evidence in Policy-Oriented Macroeconomic Modeling," CAMA Working Paper 1/2005, Australian National University. 2

King, R. G., and S. Rebelo (1999): "Resuscitating Real Business Cycles," in Handbook of Macroeconomics, Volume 1B, ed. by J. B. Taylor, and M. Woodford, pp. 927-1007. Elsevier, Amsterdam. 29

Laseen, S., J. Linde, and L. E. O. Svensson (2008): "Anticipated Instrument-Rate Paths in Policy Simulations," Manuscript, Sveriges Riksbank. 4

LeEPer, E. M. (1989): "Policy Rules, Information, and Fiscal Effects in a 'Ricardian' Model," Federal Reserve Board, International Finance Discussion Paper No. 360. 2

- (1990): "The Dynamics of Interest Rate and Tax Rules in a Stochastic Model," Federal Reserve Board, International Finance Discussion Paper No. 375. 16 
Leeper, E. M., T. B. Walker, and S.-C. S. YAng (2008): "Empirical Analysis of Fiscal Foresight," Manuscript, Indiana University. 27

Lippi, M., And L. Reichlin (1993): "The Dynamic Effects of Aggregate Demand and Supply Disturbances: Comment," American Economic Review, 83(3), 644-652. 2, 3

- (1994): "VAR Analysis, Nonfundamental Representations, Blaschke Matrices," Journal of Econometrics, 63(1), 307-325. 2

LuCAs, JR., R. E. (1976): "Econometric Policy Evaluation: A Critique," vol. 1 of CarnegieRochester Conference Series on Public Policy, pp. 104-130. North-Holland. 8

McGrattan, E. R. (1994): "The Macroeconomic Effects of Distortionary Taxation," Journal of Monetary Economics, 33(3), 573-601. 1

Mertens, K., and M. Ravn (2008): "The Aggregate Effects of Anticipated and Unanticipated U.S. Tax Policy Shocks: Theory and Empirical Evidence," EUI Working Papers, ECO 2008/05. 1, 4, 21, 26

Mountford, A., And H. Uhlig (2008): "What Are the Effects of Fiscal Policy Shocks?," Forthcoming in Journal of Applied Econometrics. 1, 23, 26

PARK, S. (1997): "The Relationship Between Government Financial Condition and Expected Tax Rates Reflected in Municipal Bond Yields," National Tax Journal, 50(1), 23-38. 27

PArker, J. A. (1999): "The Reaction of Household Consumption to Predictable Changes in Social Security Taxes," American Economic Review, 89(4), 959-973. 7

PoterbA, J. M. (1988): "Are Consumer Forward Looking? Evidence from Fiscal Experiments," American Economic Review, Papers and Proceedings, 78, 413-418. 1, 4

- (1989): "Tax Reform and the Market for Tax-Exempt Debt," Regional Science and Urban Economics, 19(3), 537-562. 27

Poterba, J. M., And L. H. Summers (1987): "Finite Lifetimes and the Effects of Budget Deficits on National Saving," Journal of Monetary Economics, 20(2), 369-391. 7

Prescott, E. C. (1986): "Theory Ahead of Business Cycle Measurement," CarneigeRochester Conference Series on Public Policy, pp. 11-44. 29

QuAH, D. (1990): "Permanent and Transitory Movements in Labor Income: An Explanation for "Excess Smoothness" in Consumption," Journal of Political Economy, 98(3), 449-475. 3

Ramey, V. A. (2007): "Identifying Government Spending Shocks: It's All in the Timing," Manuscript, University of California, San Diego. 3, 6, 25, 26

Ramey, V. A., and M. D. Shapiro (1998): "Costly Capital Reallocation and the Effects of Government Spending," Carneige-Rochester Conference Series on Public Policy, 48, 145-194. 6, 26

Roberds, W. (1991): "Implications of Expected Present Value Budget Balance: Application to Postwar U.S. Data," in Rational Expectations Econometrics, ed. by L. P. Hansen, and T. J. Sargent, pp. 163-175. Westview Press, Inc., Boulder, CO. 15

Romer, C. D., And D. H. Romer (2007a): "The Macroeconomic Effects of Tax Changes: Estimated Based on a New Measure of Fiscal Shocks," NBER Working Paper No. 13264. 1,26

Romer, C. D., And D. H. Romer (2007b): "A Narrative Analysis of Postwar Tax Changes," Manuscript, University of California, Berkeley. 1, 4, 21

Sargent, T. J. (1981): "Interpreting Economic Time Series," Journal of Political Economy, 89(April), 213-248. 16 
Schmitt-Grohe, S., And M. Uribe (2008): "What's 'News' in Business Cycles?," NBER Working Paper No. 14215. 3, 25, 27

Scholes, M. S., G. P. Willson, and M. A. Wolfson (1992): "Firms' Responses to Anticipated Reducations in Tax Rates: The Tax Reform Act of 1986," Journal of Accounting Research, 30(Supplement), 161-185. 5

Shapiro, M. D., And J. Slemrod (1995): "Consumer Response to the Timing of Income: Evidence from a Change in Tax Withholding," American Economic Review, 85(1), 274283. 7

Sims, C. A. (1972): "Money, Income, and Causality," American Economic Review, 62(4), 540-552. 16

— (1988): "Identifying Policy Effects," in Empirical Macroeconomics for Interdependent Economics, ed. by e. a. Bryant, Ralph C., pp. 308-321. The Brookings Institution, Washington, DC. 6, 26

Smets, F., And R. Wouters (2003): "An Estimated Dynamic Stochastic General Equilibrium Model of the Euro Area," Journal of the European Economic Association, 1(5), 1123-1175. 17

- (2007): "Shocks and Frictions in U.S. Business Cycles: A Bayesian DSGE Approach," American Economic Review, 97(3), 586-606. 17

Souleles, N. S. (1999): "The Response of Household Consumption to Income Tax Refunds," American Economic Review, 89, 947-958. 7

- (2002): "Consumer Response to the Reagan Tax Cuts," Journal of Public Economics, 85(1), 99-120. 7

Steigerwald, D. G., And C. Stuart (1997): "Econometric Estimation of Foresight: Tax Policy and Investment in the United States," Review of Economics and Statistics, 79(February), 32-40. 1, 4

Tutschke, W., And H. L. Vasudeva (2005): An Introduction to Complex Analysis: Classical and Modern Approaches. Chapman \& Hall/CRC, London. 19

YAnG, S.-C. S. (2005): "Quantifying Tax Effects Under Policy Foresight," Journal of Monetary Economics, 52(8), 1557-1568. 2, 7

- (2007): "Tentative Evidence of Tax Foresight," Economics Letters, 96(July), 30-37. 6,26

- (2008): "A Chronology of Postwar U.S. Federal Income Tax Policy," CAEPR Working Paper No. 2007-021. 1, 21 